\title{
Baselines for Energy Use and Carbon Emission Intensities in Hellenic Nonresidential Buildings
}

\author{
Kalliopi G. Droutsa ${ }^{1,2, *}$, Constantinos A. Balaras ${ }^{1}\left({ }^{1}\right.$, Spyridon Lykoudis $^{3}$, \\ Simon Kontoyiannidis ${ }^{1}$, Elena G. Dascalaki ${ }^{1}$ and Athanassios A. Argiriou ${ }^{2}$ (D) \\ 1 Group Energy Conservation, Institute for Environmental Research \& Sustainable Development, \\ National Observatory of Athens, 11810 Athens, Greece; costas@noa.gr (C.A.B.); skonto@noa.gr (S.K.); \\ edask@noa.gr (E.G.D.) \\ 2 Laboratory of Atmospheric Physics, Department of Physics, School of Science, University of Patras, \\ 26504 Patras, Greece; athanarg@upatras.gr \\ 3 Enargia WG, Akrita 66, 24132 Kalamata, Greece; slykoud@gmail.com \\ * Correspondence: pdroutsa@noa.gr
}

Received: 27 February 2020; Accepted: 16 April 2020; Published: 23 April 2020

\begin{abstract}
This work exploits data from 30,000 energy performance certificates of whole nonresidential (NR) buildings in Greece. The available information is analyzed for 30 different NR building uses (e.g., hotels, schools, sports facilities, hospitals, retails, offices) and four main services (space heating, space cooling, domestic hot water and lighting). Data are screened in order to exclude outliers and checked for consistency with the Hellenic NR building stock. The average energy use and $\mathrm{CO}_{2}$ emission intensities for all building uses are calculated, as well as the respective energy ratings in order to gain a better understanding of the NR sector. Finally, in an attempt to determine whether these values are representative for the various Hellenic NR building uses, their temporal evolution is investigated. The average primary energy use intensity is $448.0 \mathrm{kWh} / \mathrm{m}^{2}$ for all NR buildings, while the $\mathrm{CO}_{2}$ emissions reach $147.5 \mathrm{kgCO} / \mathrm{m}^{2}$. The derived energy baselines reveal that indoor sports halls/swimming pools have the highest energy use, while private cram schools/conservatories have the lowest, due to their operational patterns. Generally, from the four services taken into account, lighting is the most energy consuming, followed by cooling, heating and finally domestic hot water. For a total of 11 building uses, more data from the certificates will be necessary for deriving representative baselines, but, when it comes to buildings categories, more data are required.
\end{abstract}

Keywords: nonresidential buildings; baselines; EUI; energy use intensities; carbon emission intensities; EPCs; energy performance certificates

\section{Introduction}

Built environment is a key target in European (EU) policies in order to achieve a sustainable and competitive low-carbon economy. EU buildings account for nearly $40 \%$ of energy consumption and $36 \%$ of $\mathrm{CO}_{2}$ emissions [1], despite covering only $3.35 \%$ of the total land area [2]. About 35\% of the building stock is old (over 50 years) and energy inefficient, while the annual renovation rate ranges between $0.4 \%$ and $1.2 \%$ depending on the country. Therefore, increased renovation of existing buildings may lead to significant savings both in total energy consumption and $\mathrm{CO}_{2}$ emissions by about 5\% [1].

Nonresidential (NR) buildings, accounting for about a quarter of the total EU building stock, comprise a very heterogeneous sector with various building types, different building sizes and energy characteristics. Limited information is available on construction characteristics, installed systems for 
different services and energy use for the entire NR sector as well as for the various types and branches of activity.

Over the past decades, the total final energy consumption in the EU Member States (EU-28) has remained practically stable, rising only from 1033.4 million tonnes of oil equivalent (Mtoe) in 1990 to 1060.0 Mtoe in 2017 [3]. However, the final energy consumption in NR buildings has boomed by $39.2 \%$, from 110.7 Mtoe in 1990 to 154.0 Mtoe in 2017, keeping a relative stable share ranging from $11 \%$ to $15 \%$ of the total. The highest share in NR building's sector final energy consumption is electricity with $50.14 \%$, followed by gas with $30.12 \%$ [4]. For 2050, the projection is that the NR buildings' sector will account for about $17 \%$ of the total final energy use [5].

\subsection{Hellenic Nonresidential Buildings}

Based on the most recent building census, the Hellenic Nonresidential Building Stock (NR BS) includes about 690,000 exclusive-use buildings (excluding churches, monasteries, industrial buildings and parking stations), representing $21 \%$ of the national building stock, with the majority being wholesale/retail trade and offices [6]. The estimated total floor area is about $73.52 \mathrm{Mm}^{2}$, with the majority being hotels and restaurants [3], while the total final energy in 2017 reached 16.05 Mtoe increased by $15.6 \%$ compared to 1990. NR buildings consumed 2.19 Mtoe in 2017, showing an increase by $236.4 \%$ since 1990 (Figure 1). Although until 2008 the NR sector's final consumption was steadily increasing by an average of $7 \%$ per year, it was one of the first sectors that was affected by the economic recession. This is reflected by the decrease of final energy consumption since 2009, with the exception of 2012, where a slight increase occurred due to an increase of electricity consumption. From 2015, there was again a clear upward trend. Detailed information for the different NR building types is limited to only to a few studies $[7,8]$.

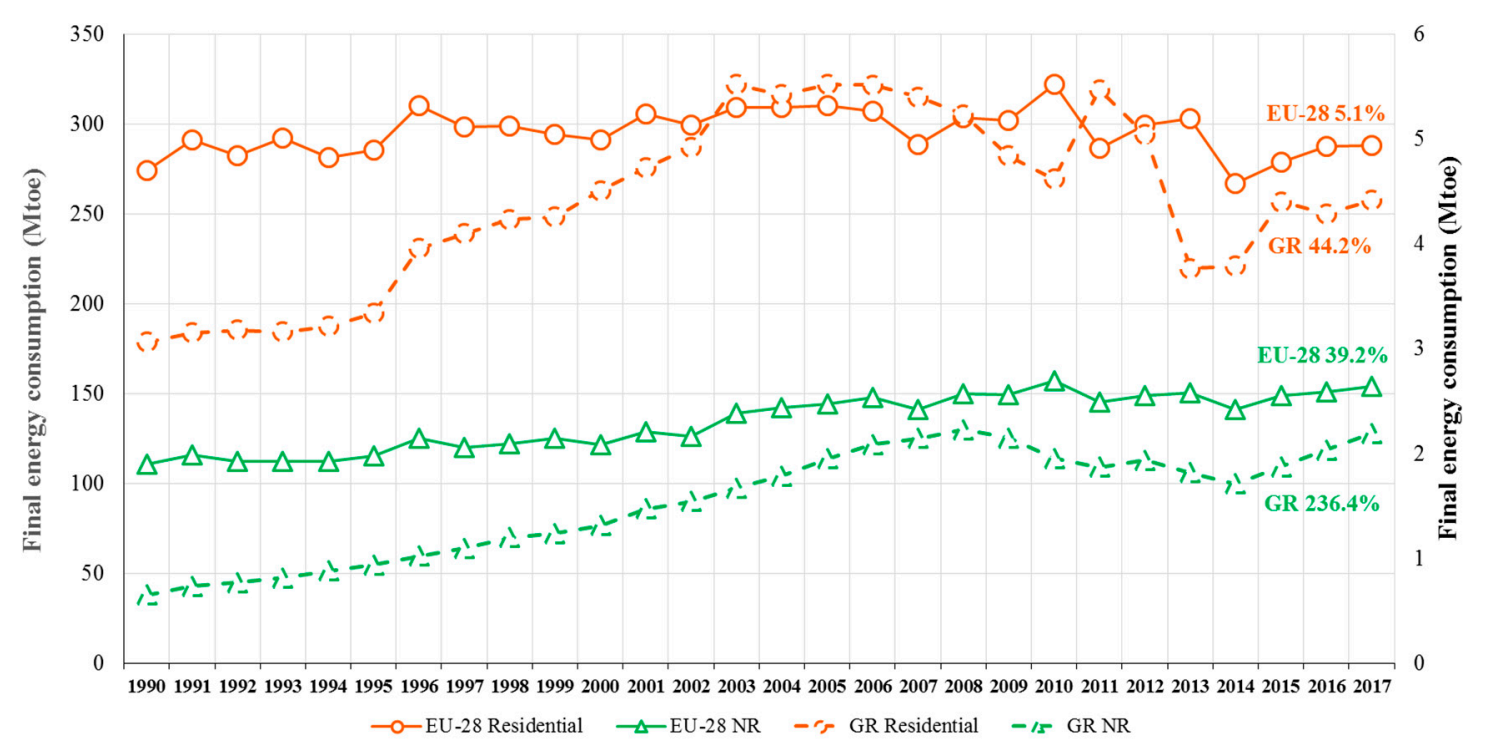

Figure 1. Time evolution of final energy consumption in residential (circles) and nonresidential (NR) (triangles) buildings for EU-28 (solid line, primary axis) and Greece (dashed line, secondary axis). The percentages refer to the corresponding increase of the final consumption in 2017 compared to 1990. (Data source [3]).

To boost energy performance of buildings, the EU has established an ambitious legislative framework that includes the Directive on Energy Efficiency (EED) recently revised by the Directive (EU) 2018/2002 amending Directive 2012/27/EU on energy efficiency, setting an EU target for energy consumption at less than 1273 Mtoe of primary energy and/or 956 Mtoe of final energy [9]. Another main instrument for addressing these challenges is the Energy Performance of Buildings Directive (EPBD) recently amended by the Directive 2018/844, promoting cost-effective building renovations, with the 
vision of a decarbonized building stock by 2050 [10]. Both directives are part of the new energy rulebook Clean Energy for All Europeans [11], according to which each Member State should draft an integrated 10-year national energy and climate plan (NECPs) for the time period 2021 to 2030.

Building energy certification plays a central role in the enhancement of the energy performance of buildings. The energy performance certificate (EPC) is a core instrument of the EPBD for existing and new buildings. The general idea behind the EPC is to influence the building market, by providing information on a building's energy use and typical energy costs and by making recommendations for cost-effective improvements [12]. Available information included in the EPCs should also be of great value for decision makers and energy planners at regional and national scales.

\subsection{Literature Overview}

While national statistical agencies provide detailed information on the residential building stock, there is a general lack of data on nonresidential buildings. Only a small number of studies have attempted to fill this gap by providing estimates on the total final and specific energy use. In most cases, these studies have focused on particular building services like offices, schools, health care or hotels. Some field work provide actual operational energy data from energy audits using utility bills or monitoring data, while others are theoretical or parametric investigations using building simulations. The challenge though remains when considering the diversities and complexities of large pool of buildings and building stocks.

As the EPC databases are progressively enriched with more data, studies have emerged in different countries that exploit this information to map the characteristics of different categories of buildings and gain a better insight on their energy performance. The majority of them focus on residential buildings. This is to be expected since most EPCs throughout Europe have been issued for dwellings or houses that are commonly rented or sold, and residential buildings constitute the majority of the existing building stock.

For example, in Italy, studies have been carried out by analyzing approximately 90,000 energy certificates of flats in order to establish a method for estimating primary energy for space heating and the main building characteristics (e.g., envelope U-values) that influence their energy performance [13]. According to another study in Italy, exploiting about 17,600 energy certificates for residential buildings, average primary energy for the representative old buildings (up to 1992), ranges between $392-178 \mathrm{kWh} / \mathrm{m}^{2}$ for existing buildings, $321-158 \mathrm{kWh} / \mathrm{m}^{2}$ for partially renovated buildings and $113-53 \mathrm{kWh} / \mathrm{m}^{2}$ after major renovations [14]. In Spain, almost 130,000 energy performance certificates for existing residential buildings were examined [15]. Most were rated at a low energy class E (53.6\%). On average, single-family houses use $248.0 \mathrm{kWh} / \mathrm{m}^{2}$, which is higher than individual dwellings that average $183.2 \mathrm{kWh} / \mathrm{m}^{2}$. In Switzerland, the thermal performance of the residential building stock was analyzed using about 10,400 cantonal EPCs. The results revealed that about $75 \%$ of the buildings' envelope are below new buildings' standards and about $50 \%$ of the surface area is still heated by inefficient oil-fired boilers, confirming the high potential for significant energy savings from thermal renovations of the Swiss residential building stock [16]. Finally, an initial study in Greece [17] analyzing early EPC data, concluded that the average primary energy use for residential buildings is $260 \mathrm{kWh} / \mathrm{m}^{2}$, with thermal energy accounting for $72 \%$. MFH have a lower energy consumption averaging $241 \mathrm{kWh} / \mathrm{m}^{2}$ compared to $367 \mathrm{kWh} / \mathrm{m}^{2}$ for SFH.

As the number of issued EPCs grows with time, so does the available number of certificates that have been issued for NR buildings. As a result, studies have progressively been performed exploiting this valuable resource of information. For example, an overview of the NR sector in different countries focusing on building characteristics, energy performance, efficiency measures and energy savings is presented in [18]. A more detailed focus is given to office buildings, which represent the most common building category in the database. The average consumption of existing offices before renovation is $203 \mathrm{kWh} / \mathrm{m}^{2}$, while for new office buildings it is considerably lower at $122.9 \mathrm{kWh} / \mathrm{m}^{2}$. 
In Catalonia, Spain, researchers exploiting data from about 14,000 certificates found that offices have an average annual energy use of $207.4 \mathrm{kWh} / \mathrm{m}^{2}$. Their energy ranking is mostly labeled in classes-C and -D (64\%), while high energy ratings at the top ranked energy class $\mathrm{A}$ and $-\mathrm{B}$ are limited to $\sim 8 \%$ of the database [19]. NR buildings in Spain, were found to have slightly better energy performance than residential buildings, with an average energy consumption of $317.8 \mathrm{kWh} / \mathrm{m}^{2}$ [15].

In Sweden, the current energy consumption baseline for NR buildings is defined by exploiting data from about 186,000 EPCs issued for some common commercial building types [20]. Accordingly, the average energy use is $175 \mathrm{kWh} / \mathrm{m}^{2}$ for hotels and restaurants, $151 \mathrm{kWh} / \mathrm{m}^{2}$ for rental premises-offices, $169.2 \mathrm{kWh} / \mathrm{m}^{2}$ for healthcare facilities, $171.8 \mathrm{kWh} / \mathrm{m}^{2}$ for schools and $174 \mathrm{kWh} / \mathrm{m}^{2}$ for sports facilities [20]. In another study, energy use in the public sector office stock in England and Wales is explored using a database of 2,600 certificates. The electrical and fossil-thermal energy use profiles for different office types range between $68-211 \mathrm{kWh} / \mathrm{m}^{2}$ and $132-53 \mathrm{kWh} / \mathrm{m}^{2}$ respectively [21]. The energy use in English schools was derived using data from 8500 EPCs of primary or secondary schools [22]. Electrical energy use ranged between $44-50 \mathrm{kWh} / \mathrm{m}^{2}$, and thermal energy use between $138-140 \mathrm{kWh} / \mathrm{m}^{2}$ [22]. Finally, from an earlier study of a limited number of certificates for NR buildings in Greece, the average primary energy use averaged $459 \mathrm{kWh} / \mathrm{m}^{2}$, ranging from $211 \mathrm{kWh} / \mathrm{m}^{2}$ for schools to $1023 \mathrm{kWh} / \mathrm{m}^{2}$ for hospitals [17].

This work exploits for the first time the most comprehensive data included in the national EPC electronic repository (buildingcert) over a nine-year period (i.e., from January 2011 to the end of 2019). The main novelty and objective of the present work is to present a well-structured, modular methodology for the exploitation of data included in EPC databases, in order to fill the gap of knowledge on the performance of the existing NR building stock. The proposed methodology provides a complete approach, starting with the data quality control, the data clustering into building uses and building categories, and the definition of practical baselines on the energy use and $\mathrm{CO}_{2}$ emissions for different clusters. The work demonstrates the application using the national EPC database in Greece and further investigates whether the derived baselines can be regarded as typical for the Hellenic building stock. The paper is structured as follows: Section 2 provides an overview of the national EPC database. Section 3 presents the method used in the analysis for deriving the baselines and for assessing the time evolution of the indicators. Section 4 applies the overall approach to the national EPC database and presents the results of the analysis. Finally, Section 5 discusses the main findings, outlines the limitations of the work and concludes by summarizing the main findings.

\section{National EPC Database}

The national regulation on the energy performance of buildings, KENAK, which was the EPBD transposition in Greece, was implemented in 2010 and updated in July 2017, imposing stricter building requirements. The regulation is supported by four Technical Guidelines that govern its practical implementation, first published in 2010 and revised in 2012 and in 2017. The normative calculations for estimating the building's energy demand are in accordance to the European standards (e.g., EN 13790) using the quasi-steady-state monthly method and are included in the official national calculation engine (TEE-KENAK) [23]. The national tool was initially developed in 2010 and was periodically updated to comply with the evolution of the national Technical Guidelines.

Based on the Technical Guidelines, the end uses taken into account for the assessment of the building's energy performance are heating, cooling, domestic hot water (DHW) and lighting. Mechanical ventilation is included in heating and cooling accordingly. Other office and miscellaneous plug loads (e.g., electronic or computing equipment) and process loads (e.g., elevators, escalators) are not considered.

According to the Hellenic labelling scheme, the energy rating of a building is based on the ratio of its calculated primary energy use to that of the corresponding reference building. As a result there are nine energy classes ranging from class $\mathrm{G}$ (lowest performance) up to class A+ (highest performance). The reference building is an exact copy of the audited building, complying with the minimum 
requirements for specific envelope and systems characteristics defined in the national regulation, e.g., U-values, system efficiencies etc. The reference building is ranked by definition at energy class B. A building can be characterized as a nearly zero-energy building (nZEB) when it is ranked at least at energy class A for new constructions, and at energy class B+ for renovated buildings [24].

Based on the national Technical Guidelines, Greece is divided in four climate zones. The coverage was determined on the basis of the heating degree days (HDD), i.e., zone A in the south with mild conditions (averaging 859 HDD), to zone D in the north with the coldest conditions (averaging 2260 HDD).

In addition, the Technical Guidelines define a total of 60 different building types for the NR building sector, grouped into seven building categories (BC I-VII). In this work, the building types are further grouped into 30 building uses (BU 1-30) identified in Table 1, based on the criterion that each group includes similar building types sharing the same common assumptions and default values (i.e., building types hospital and clinic are grouped in one building use BU20-hospital/clinic). For example, BU20 refers to hospital/clinic with continuous annual operation (i.e., $24 \mathrm{hr} /$ day, 7 days/week, 12 months/year); operative temperature at $22{ }^{\circ} \mathrm{C}$ for heating and $26{ }^{\circ} \mathrm{C}$ for cooling and operative relative humidity at 35\% and 50\%, respectively; fresh air requirements at $10.5 \mathrm{~m}^{3} / \mathrm{hr} / \mathrm{m}^{2}$ heated floor area; DHW consumption, depending on the bed capacity, at $22.00-43.90 \mathrm{~m}^{3} /$ bed; annual artificial lighting hours at $7571 \mathrm{hr}$, internal heat gains from occupants at $27 \mathrm{~W} / \mathrm{m}^{2}$ heated floor area and from appliances at $7.5 \mathrm{~W} / \mathrm{m}^{2}$ heated floor area (internal heat gains from lighting are calculated based on the installed power) [25]. Note that, for some building uses (e.g., BU17-primary/secondary school), the DHW is considered negligible and is not taken into account in the calculations.

As of January 2011, issuing an EPC is compulsory for all buildings that are being sold and for whole buildings that are being rented. From January 2011 until December 2019, a total of about 1,820,000 EPCs have been issued, out of which $16.9 \%$ are for NR buildings. These include whole buildings, i.e., stand-alone buildings with the same use (e.g., office, school) and part buildings, i.e., building units (e.g., office spaces) in a multi-floor building. The exploited information from the EPCs include the calculated primary energy use per unit floor area $\left(\mathrm{kWh} / \mathrm{m}^{2}\right)$ for the total consumption (EUIp) and for the different end uses, i.e., space heating (EUIp,H), space cooling (EUIp,C), domestic hot water (EUIp,DHW) and lighting (EUIp,L), as well as the total $\mathrm{CO}_{2}$ emissions per unit floor area $\left(\mathrm{kgCO}_{2} / \mathrm{m}^{2}\right)$. According to $\mathrm{KENAK}$, the national primary energy conversion factors per energy carrier are 2.9 for electricity, 1.1 for heating oil and 1.05 for natural gas. Correspondingly, the carbon emission national conversion factors are $0.989 \mathrm{kgCO}_{2} / \mathrm{kWh}, 0.264 \mathrm{kgCO}_{2} / \mathrm{kWh}$ and $0.196 \mathrm{kgCO} / \mathrm{kWh}$. 
Table 1. Energy use $\left(\mathrm{kWh} / \mathrm{m}^{2}\right)$ and $\mathrm{CO}_{2}$ emission $\left(\mathrm{kg} / \mathrm{m}^{2}\right)$ intensities for the different building categories and building uses in the NR Dbase.

\begin{tabular}{|c|c|c|c|c|c|c|c|}
\hline Building Category Building Use & $\begin{array}{c}\text { \# Bldgs/Heated } \\
\text { Area }\left(\mathrm{m}^{2}\right)\end{array}$ & $\begin{array}{c}\text { EUIp,H } \\
\text { Av [Min-Max] }\end{array}$ & $\begin{array}{c}\text { EUIp,C } \\
\text { Av [Min-Max] }\end{array}$ & $\begin{array}{c}\text { EUIp,DHW } \\
\text { Av [Min-Max] }\end{array}$ & $\begin{array}{c}\text { EUIp,L } \\
\text { Av [Min-Max] }\end{array}$ & $\begin{array}{c}\text { EUIp } \\
\text { Av [Min-Max] }\end{array}$ & $\begin{array}{l}\mathrm{CO}_{2} \text { Emissions } \\
\mathrm{Av} \text { [Min-Max] }\end{array}$ \\
\hline BCI. Temporal Residence & $6393 / 3,778,978$ & 57.2 & 129.5 & 40.5 & 170.3 & 397.3 & 127.9 \\
\hline BU1-Hotel (annual) & $940 / 1,066,594$ & $132.5[0.1-586.2]$ & $143.5[5.5-451.8]$ & $70.2[0.0-287.9]$ & 203.3 [2.9-689.0] & $549.2[102.0-1347.6]$ & $172.9[25.4-445.2]$ \\
\hline BU2-Hotel (summer) & $2270 / 1,844,069$ & $7.4[0.1-29.7]$ & $120.0[8.9-453.5]$ & $24.2[0.0-122.4]$ & $143.9[12.7-393.0]$ & $259.4[66.4-797.9]$ & $97.0[15.2-272.4]$ \\
\hline BU3-Guest house (annual) & $992 / 279,233$ & $168.0[0.5-665.4]$ & $146.7[1.7-503.3]$ & $64.0[0.0-288.1]$ & $224.4[12.2-583.6]$ & $602.8[67.2-1584.0]$ & $191.1[31.9-540.7]$ \\
\hline BU4-Guest house (summer) & $2073 / 524,446$ & $8.7[0.1-35.2]$ & $123.3[3.5-425.9]$ & $22.0[0.0-117.1]$ & $159.7[2.9-449.9]$ & $313.4[11.9-849.3]$ & $103.3[18.1-289.9]$ \\
\hline BU5-Guest house (winter) & 9/3882 & 258 [117.2-503.4] & $6.0[1.0-17.0]$ & $22.9[13.2-37.0]$ & 146.2 [118.2-204.3] & 433.6 [263.1-659.3] & $128.5[79.2-177.5]$ \\
\hline BU6-Boarding school/Quarters/Dormitory & $109 / 60,754$ & $143.9[0.5-763.7]$ & $152.2[8.1-403.7]$ & $63.4[0.0-329.9]$ & $238.6[80.4-475.8]$ & $597.5[155.8-1414.5]$ & $194.6[52.7-497.7]$ \\
\hline BCII. Public assembly & $5955 / 1,573,991$ & 206.6 & 257.4 & 101.2 & 130.9 & 695.8 & 220.2 \\
\hline BU7-Restaurant & $2597 / 439,908$ & $235.5[0.4-905.5]$ & $272.0[3.2-766.1]$ & $165.8[0.0-410.8]$ & $140.2[0.2-500.1]$ & 813.4 [150.1-1945.7] & 257.1 [51.0-660.9] \\
\hline BU8-Pastry/Coffee shop & $2153 / 252,214$ & $353.5[0.1-1405.1]$ & $321.7[5.7-938.2]$ & $49.8[0.0-81.5]$ & $174.9[0.3-564.5]$ & $899.7[100.8-2243.5]$ & $277.6[33.4-1294.5]$ \\
\hline BU9-Night/Music hall & $428 / 154,744$ & $104.5[0.2-371.5]$ & $121.1[8.8-408.4]$ & $53.5[0.0-86.0]$ & $45.4[5.8-208.7]$ & $324.5[74.6-707.3]$ & $103.5[24.9-239.4]$ \\
\hline BU10-Theater/Cinema & $50 / 29,467$ & $103.8[14.9-337.6]$ & $206.5[36.9-431.2]$ & & $74.3[22.7-290.4]$ & 384.6 [183.3-701.8] & $126.8[62.6-239.6]$ \\
\hline BU11-Exhibition hall/Museum & $120 / 135,487$ & $79.0[3.1-317.8]$ & $166.0[8.4-414.0]$ & & $68.1[4.8-210.3]$ & $312.5[65.8-632.5]$ & $102.6[22.4-210.5]$ \\
\hline BU12-Conference hall/Auditorium/Cour & $16 / 23,703$ & 71.3 [14.0-211.9] & $135.2[51.1-296.1]$ & & $105.1[40.9-254.2]$ & 311.6 [145.0-657.3] & $104.0[48.4-211.3]$ \\
\hline BU13-Bank & $69 / 43,748$ & $66.7[4.4-215.4]$ & $77.7[4.4-229.6]$ & & $114.4[17.7-219.8]$ & 257.8 [69.6-487.1] & $85.5[23.7-160.4]$ \\
\hline BU14-Multi-purpose venue & $278 / 160,915$ & $107.1[0.3-396.9]$ & $138.0[5.3-432.0]$ & & $83.1[1.3-250.8]$ & $328.2[58.6-740.8]$ & $106.9[20.0-252.9]$ \\
\hline BU15-Indoor Sports hall/Swimming Pool & $244 / 333,805$ & $241.4[0.1-853.4]$ & $384.0[41.2-792.5]$ & $196.0[0.0-704.6]$ & $182.6[48.3-455.0]$ & 1003.9 [162.4-1971.9] & $318.6[55.4-673.1]$ \\
\hline BCIII. Educational & $1336 / 1,645,060$ & 105.1 & 12.5 & & 64.2 & 181.6 & 53.3 \\
\hline BU16-Kindergarten & $152 / 45,203$ & $134.8[12.2-427.6]$ & $4.1[0.2-13.9]$ & & 49.6 [15.7-99.4] & 177.6 [41.5-491.1] & 50.5 [14.0-159.8] \\
\hline BU17-Primary/Secondary School & $898 / 1,360,392$ & $107.8[1.8-421.7]$ & $8.8[0.0-38.6]$ & & 55.6 [14.1-118.3] & $172.0[41.7-647.4]$ & $49.2[13.9-150.9]$ \\
\hline BU18-University/College/Lecture rooms & $116 / 192,895$ & $87.6[5.5-316.8]$ & $40.4[3.2-111.7]$ & & $126.0[17.8-308.8]$ & $254.0[51.3-567.2]$ & $82.7[17.5-192.3]$ \\
\hline BU19-Private cram school/Conservatory & $170 / 46,571$ & $80.7[1.4-326.6]$ & $10.9[0.0-45.4]$ & & $75.9[11.8-150.9]$ & $167.2[26.2-396.1]$ & $53.6[8.9-128.1]$ \\
\hline BCIV. Health and Social Welfare & $796 / 2,068,699$ & 221.3 & 212.3 & 27.7 & 197.0 & 657.8 & 205.6 \\
\hline BU20-Hospital/Clinic & $161 / 1,644,060$ & $234.1[4.3-771.6]$ & $232.5[37.2-820.1]$ & $28.7[0.0-112.4]$ & $205.4[37.7-446.0]$ & $700.3[222.4-1707.0]$ & 218.9 [69.9-555.0] \\
\hline BU21-Health care/Rural outpatient clinic/Consultation room & $230 / 162,686$ & $154.8[9.2-630.9]$ & $121.5[8.3-302.5]$ & $13.6[0.0-41.8]$ & $157.5[8.3-318.5]$ & $446.7[101.8-1009.4]$ & $141.3[34.8-328.9]$ \\
\hline BU22-Foundling hospital/Nursing home/Asylum & $119 / 141,938$ & $255.0[8.6-822.6]$ & 208.4 [28.4-577.5] & $37.6[0.0-159.5]$ & $256.9[78.2-621.1]$ & $757.1[219.5-1620.3]$ & $235.4[66.5-530.8]$ \\
\hline BU23-Nursery & $286 / 120,016$ & $95.7[1.7-345.9]$ & $63.7[0.7-208.4]$ & $20.6[0.0-70.8]$ & $63.8[10.8-142.3]$ & $243.5[50.7-548.1]$ & 75.9 [17.3-165.8] \\
\hline BCV. Justice/public order/safety & $22 / 38,474$ & 160.6 & 127.4 & & 278.5 & 566.5 & 182.6 \\
\hline BU24-Police station & $22 / 38,474$ & $160.6[15.7-637.2]$ & $127.4[37.2-222.8]$ & & $278.5[60.8-579.1]$ & 566.5 [288.2-896.3] & $182.6[83.7-278.1]$ \\
\hline BCVI. Commercial & $11,564 / 3,293,795$ & 143.2 & 159.9 & 1.9 & 148.6 & 453.4 & 147.6 \\
\hline BU25-Shopping mall/Large retail building & $435 / 759,465$ & $63.9[0.9-312.0]$ & $141.7[3.1-504.8]$ & & $149.4[2.6-389.4]$ & $354.6[54.6-822.6]$ & $118.6[26.7-280.8]$ \\
\hline BU26-Small retail building/Drugstore & $11,022 / 2,508,652$ & $167.1[0.1-729.6]$ & $165.3[0.1-588.4]$ & & $148.3[0.2-342.3]$ & 480.5 [63.5-1399.8] & $155.5[9.9-477.1]$ \\
\hline BU27-Fitness center & $53 / 22,397$ & $138.0[1.3-575.4]$ & $173.7[8.6-507.0]$ & $268.2[0.1-565.3]$ & $164.1[29.3-335.4]$ & $744.1[248.8-1325.9]$ & $237.0[79.2-452.6]$ \\
\hline BU28-Barber shop/Hair salon & $54 / 3280$ & $239.6[24.3-577.0]$ & 156.4 [16.5-441.9] & $66.4[0.0-105.3]$ & $146.3[45.0-335.4]$ & 608.8 [320.8-1058.1] & 195.7 [78.9-361.2] \\
\hline BCVII. Office/Library & $2728 / 2,308,452$ & 100.7 & 121.2 & & & 354.3 & 115.4 \\
\hline BU29-Office & $2706 / 2,292,503$ & $100.5[0.4-483.4]$ & $121.4[0.8-438.5]$ & & $133.2[5.2-299.7]$ & 354.7 [29.7-952.8] & $115.5[16.7-325.3]$ \\
\hline BU30-Library & $18 / 15,949$ & $130.5[10.9-421.9]$ & 99.7 [24.8-250.2] & & $81.4[38.6-148.3]$ & 303.5 [144.6-581.0] & $94.9[49.3-160.0]$ \\
\hline NR Dbase & $28,970 / 14,707,447$ & 128.0 & 147.2 & 25.5 & 147.5 & 448.0 & 142.9 \\
\hline
\end{tabular}

Empty cells refer to BUs that have no DHW in the calculations according to the national regulation. 


\section{Method}

The following sections provide an overview of the approach used in this work to exploit the available information from the EPCs and derive practical baselines on the energy use and $\mathrm{CO}_{2}$ emissions for NR buildings. The evolution of these baselines over time are also investigated in order to conclude whether they can be considered as representatives. The main steps of the method used in this work is illustrated in Figure 2 and elaborated in the following sections.

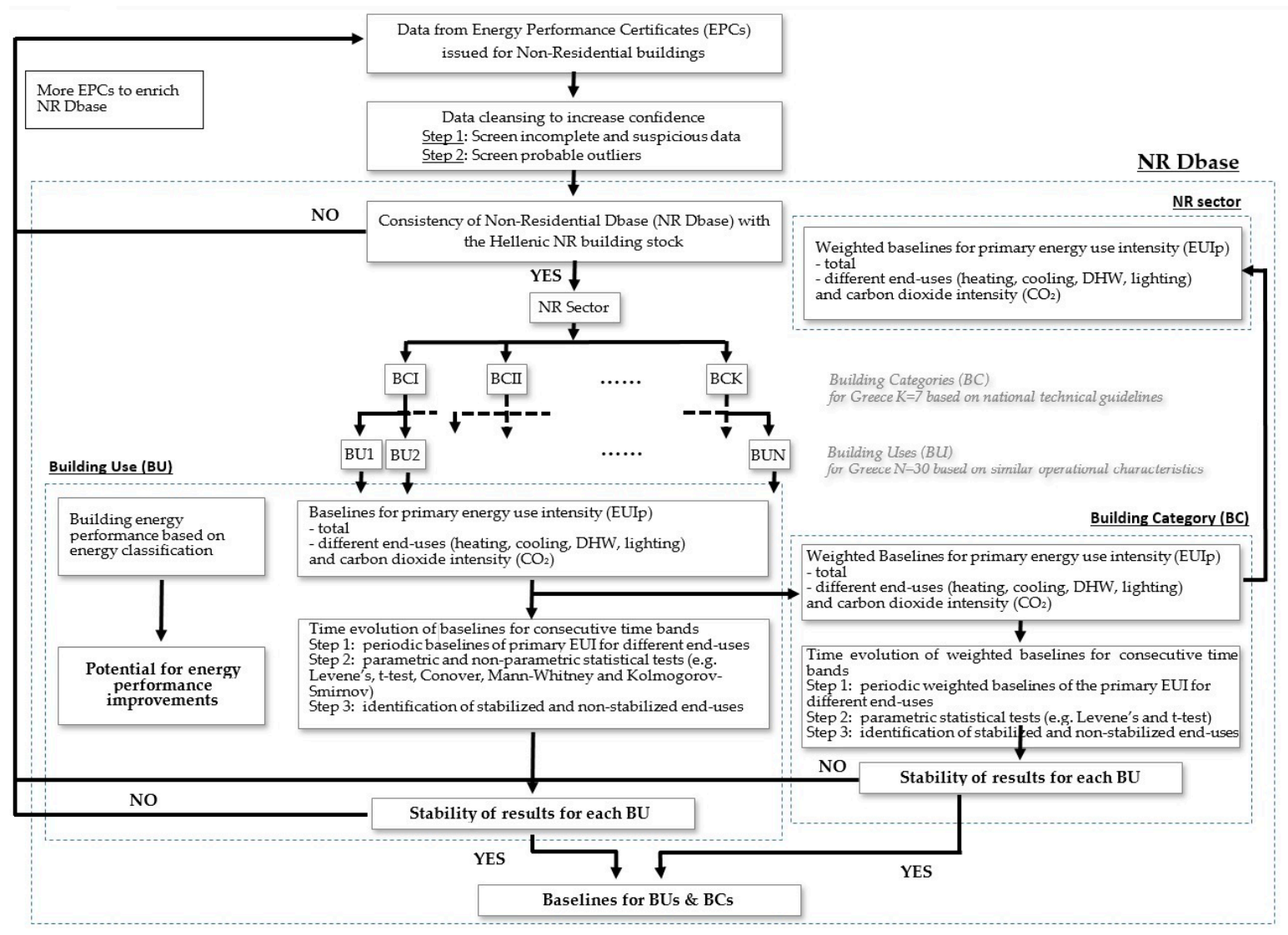

Figure 2. The main steps of the method.

\subsection{Data Cleansing}

Since EPC databases are one of the main sources of information about the energy use for various types of buildings, the quality of stored data is of vital importance [26]. By 2014, some kind of quality control processes of the EPCs were established in all EU member states [27]. In Greece, the first level data quality controls are performed by the responsible authority [28]. To further increase data confidence and ensure compliance, the available data were also screened before being used in the following analysis. The data cleansing process involved a series of checks in order to remove incomplete, erroneous, or otherwise suspicious data, thus ensuring that the data used are within reasonable limits and that derived baselines are reliable [29]. Accordingly, EPCs were excluded if they were:

- Not complying with the national regulation requirements;

- Issued by penalized energy inspectors;

- Issued in the initial phase of the national energy efficiency subsidy program;

- Incomplete or not finally submitted;

- Including negative values, heated floor area greater than or less than $20 \%$ of the total floor area, zero $\mathrm{CO}_{2}$ emissions (when the energy carrier is not exclusively biomass), EUIp less than $5 \mathrm{kWh} / \mathrm{m}^{2}$ (for buildings with no RES) and greater than $8000 \mathrm{kWh} / \mathrm{m}^{2}$; 
The resulting valid data for NR buildings reached about 235,000 EPCs or $76 \%$ of the initial database. As expected, most of the valid EPCs ( $86 \%$ ) were issued for part buildings. However, since whole buildings are considered more representative of the various building uses, the following analysis is based on the available data for whole buildings. Accordingly, the valid data for NR whole buildings are about 31,700 EPCs.

Most data sets contain errors that can be identified as outliers having unusually large or small values. Such data may influence the statistical analysis and bias the results. A widely used method to screen data for outliers is the so-called Tukey boxplot method [30]. The method employs the interquartile range (IQR) as a measure of how spread-out the values are, being equal to the difference between 75th $(\mathrm{Q} 3)$ and 25th $(\mathrm{Q} 1)$ percentiles. Tukey defined Q1 $-1.5 \times \mathrm{IQR}$ and Q3 + 1.5 $\times$ IQR as "inner fences", Q1 - $3 \times$ IQR and Q3 + 3 $\times$ IQR as "outer fences", the observations between an inner fence and the corresponding outer fence as "possible outliers", and anything beyond outer fences as "probable outliers".

In order to decide on the proper selection of the cut-off point one needs to know the shape of the empirical distribution of the data. Each end use of the different BUs was treated separately, since in the NR sector, BUs have very different energy profiles. Skewness and kurtosis are good indicators for nonsymmetrical distributions and the size and direction of the tails. Skewness is the degree of distortion from a symmetrical distribution. Skewness values between -0.5 and 0.5 indicate fairly symmetrical data, while skewness values less than -1 or greater than 1 correspond to skewed data. Kurtosis is actually the measure of outliers present in the distribution. The standard normal distribution has a kurtosis of three [31]. In more than $90 \%$ of the cases, the skewness of the end uses' empirical distribution differed significantly (at the $95 \%$ confidence level) from that corresponding to a normal distribution, reaching values higher than 10 in some cases. Similarly, more than $85 \%$ of the kurtosis values differed significantly (at the $95 \%$ confidence level) from those corresponding to a normal distribution, being, in some cases, higher than 100 . The results indicated nonsymmetrical data distributions with long, heavy tails to the right (high positive skewness values).

The distance from normality was confirmed by a set of Kolmogorov-Smirnov tests against the data following the normal distribution [32]. Accordingly, as an additional quality control step, the valid EPCs for NR whole-buildings were further screened in order to identify and exclude outliers, using the aforementioned Tukey boxplot method. For more than half of the valid EPCs setting the cut-off point at the inner fence would label more than 15\% (and up to 37\%) of the cases as outliers, whereas for the outer fence the percentage of the data points considered outliers was more reasonable, less than $10 \%$ for about $75 \%$ of the cases (and up to $24 \%$ ).

Applying the additional screening on the valid data for NR whole buildings (setting the cut-off point at the outer fence), the resulting database for NR whole buildings comprises about 28,800 EPCs, referred to as the NR Dbase in the following analysis.

\subsection{NR Dbase}

In order to justify the use of the resulting average values as baselines for the different BUs, the work assesses whether the NR Dbase could be considered representative of the Hellenic NR BS. The distribution of available data is defined for the number of buildings and size (i.e., heated floor area) and is then compared to the corresponding distribution of the NR BS from official national statistics $[3,6]$. In addition, the spatial distributions of the audited buildings according to climate zones, as well as to the four major socioeconomic regions (NUTS1 regions) are defined and compared to the corresponding distribution of the NR BS [6]. In case of similarity in profiles, the NR Dbase can be considered representative. Otherwise the results should be used with caution and the definition of baselines should be repeated at a later date when more data become available. 


\subsection{Primary Energy Use and $\mathrm{CO}_{2}$ Intensities}

The calculated primary energy use intensity is derived for the total consumption and for the four end uses taken into account for each $\mathrm{BU}$, since these independent variables can give a better insight than the aggregated total. Similarly, the total $\mathrm{CO}_{2}$ emissions per unit floor area are also derived for all BUs. The corresponding averages of the primary energy use and $\mathrm{CO}_{2}$ intensities, for the different building categories, are calculated as the weighted average of all building uses included in the category, using the total heated area as weight. Finally, the average primary energy use and $\mathrm{CO}_{2}$ intensities for the entire Hellenic NR sector are calculated as the weighted average of the corresponding values of the different building categories.

\subsection{Building Energy Performance}

In order to evaluate the energy performance of NR buildings, the distribution of the audited buildings into the nine energy classes of the national rating system is considered. In an attempt to compare the BUs as to their energy behavior, the energy classes are given a score from 1 (highest energy class $A+$ ) to 9 (lowest energy class G). The weighted average energy score for each BU (based on the number of buildings in each energy class) is then calculated, providing an indication about the average energy behavior of each BU.

Further analysis also investigates the distribution of energy use intensity per energy class for all the BUs, as well as for the entire NR sector. This can provide some insight on the gap of the audited buildings from the excellent energy performance.

\subsection{Time Evolution of Intensities}

Issued EPCs for whole NR buildings have increased from 184 by the end of 2011 to 28,790 by the end of 2019. The following analysis focuses on the differences between the periodic average EUIp values over time, in order to conclude whether they can be considered stabilized and therefore representative.

As a first step, the time series of the EPCs in NR Dbase is organized in the cumulative datasets of consecutive years. For the available national database, this refers to nine time bands, covering the entire period of implementation and available EPCs from 2011 until 2019. For example, the first time band includes the data from the EPCs issued up to 2011, the second time band includes all the data issued up to 2012, and so forth till the ninth (last) time band that includes the entire database up to 2019. The periodic averages of EUIp and $\mathrm{CO}_{2}$ and the respective standard errors are then calculated for all $30 \mathrm{BUs}$ for each time band.

As a second step, the degree of differentiation of the specific indicators (e.g., EUIp for the different end uses, $\mathrm{CO}_{2}$ emissions) is investigated among pairs of consecutive time bands. For the available national database, this refers to eight pairs of the available data. For example, the first pair considers the data from the EPCs issued up to 2011 and those issued up to 2012. The second pair considers the data from the EPCs issued up to 2012 and those issued up to 2013 and so forth till the eighth pair with data from the EPCs issued up to 2018 and those issued up to 2019. Initially, two parametric tests are performed for each building use for the comparison of their (a) variances, and (b) averages.

Available statistical methods testing for the homogeneity of variance include Barlett's, Hartley's, Cochran's and Levene's tests [33]. From these, Levene's test is the most common assessment for homogeneity of variance, since it does not require normality of the underlying data. In this work, the vast majority of EPCs' probability distribution per BU is non-normal, as already discussed in Section 3.1. Accordingly, the Levene's test [34] is used to evaluate the possible changes in the variances of the indicators (e.g., total primary energy use intensity and for the different end uses) among pairs of consecutive time bands. The null hypothesis being tested is that the population variances of the two samples are equal, so in other words there is no change in their variance with the addition of new data.

One of the most common tests for equality of averages of two unrelated samples is the t-test [35]. In this work, the two independent samples' $t$-test was used for equal or unequal variances, depending on 
the Levene's test results, in order to check for possible changes in the average values among consecutive time bands. The null hypothesis is that the population average values of the two unrelated samples are equal.

Supplementary to the parametric tests, three nonparametric tests are also applied to compare the respective frequency distributions. The complementary nonparametric tests include the Conover test for equality of variances, the Mann-Whitney $(\mathrm{M}-\mathrm{W})$ test for equality of the averages, and the Kolmogorov-Smirnov (K-S) homogeneity test [32].

A crucial step in these parametric and nonparametric tests is evaluating how compatible the sample data is with the null hypothesis. This probability is called the p-value. The null hypothesis is rejected for small p-values (typically $\leq 0.05$ ) as they indicate strong evidence against it. The null hypothesis is retained for large p-values $(>0.05)$.

These two parametric and three nonparametric tests are applied for all BUs, for the specific indicators across the eight pairs of consecutive time bands. The results include the statistic values and the p-values of the respective tests. A dataset is characterized as stabilized (S) when there are no failures of the null hypotheses for any of the five tests, for all pairs of the time bands. If any two pairs of time bands fail in the variance tests, the dataset is characterized almost stabilized (AS), provided that the average tests and the K-S homogeneity test have no failures. In all other cases, the dataset is considered as nonstabilized (NS).

A similar approach is followed for testing the results for the different building categories (BCI-BCVII), applying the two parametric tests. Accordingly, the Levene's test and the appropriate two independent samples' $t$-test were used to test the weighted averages of EUIp for the different end uses and for the $\mathrm{CO}_{2}$ emissions. The use of nonparametric tests is not suitable since the database is composed of weighted averages for the different indicators.

\section{Results}

\subsection{NR Dbase}

The profiles of the number of buildings and the total floor area for the NR BS and NR Dbase are illustrated in Figure 3. The buildings included in the NR Dbase comprise only $4.1 \%$ of the NR BS, but the total floor area the percentage reaches $23.5 \%$. Figure $3 \mathrm{~b}$ indicates that the breakdown of the data available in the NR Dbase into the various building uses is similar to that of the national building stock.

The spatial distribution of buildings according to climate zones as well as NUTS1 region for the NR BS and NR Dbase are illustrated in Figure 4. The available data in the NR Dbase are distributed throughout the country, resembling the distribution of the national building stock, according to NUTS1. On the other hand, it appears that the number of certificates issued in the two southern zones (A and $B$ ) is relatively higher than the northern/colder zones (C and D). These observations should be taken into account when considering national average values.

\subsection{Primary Energy Use and $\mathrm{CO}_{2}$ Intensities}

The derived indicators of energy use and $\mathrm{CO}_{2}$ emissions for the different building categories and building uses are summarized in Table 1. The lowest calculated EUIp corresponds to BU19-private cram school/conservatory averaging $167.2 \mathrm{kWh} / \mathrm{m}^{2}$, since these buildings have limited operating and artificial lighting hours and small internal heat gains from occupants and appliances, while DHW is not considered. On the other hand, BU15-indoor sports hall/swimming pool buildings have the highest calculated EUIp, averaging $1003.9 \mathrm{kWh} / \mathrm{m}^{2}$, due to their high fresh air requirements, high internal loads and high DHW demand. For information, the corresponding values for residential whole buildings range from $252.7 \mathrm{kWh} / \mathrm{m}^{2}$ in multifamily houses (MFH) to $383.5 \mathrm{kWh} / \mathrm{m}^{2}$ in single-family houses (SFH). The average $\mathrm{CO}_{2}$ emissions for NR and residential buildings range from $49.2 \mathrm{~kg} / \mathrm{m}^{2}$ (BU17-primary/secondary school) to $318.6 \mathrm{~kg} / \mathrm{m}^{2}$ (BU15) and from $72.2 \mathrm{~kg} / \mathrm{m}^{2}$ in MFH to $99.5 \mathrm{~kg} / \mathrm{m}^{2}$ in SFH. 

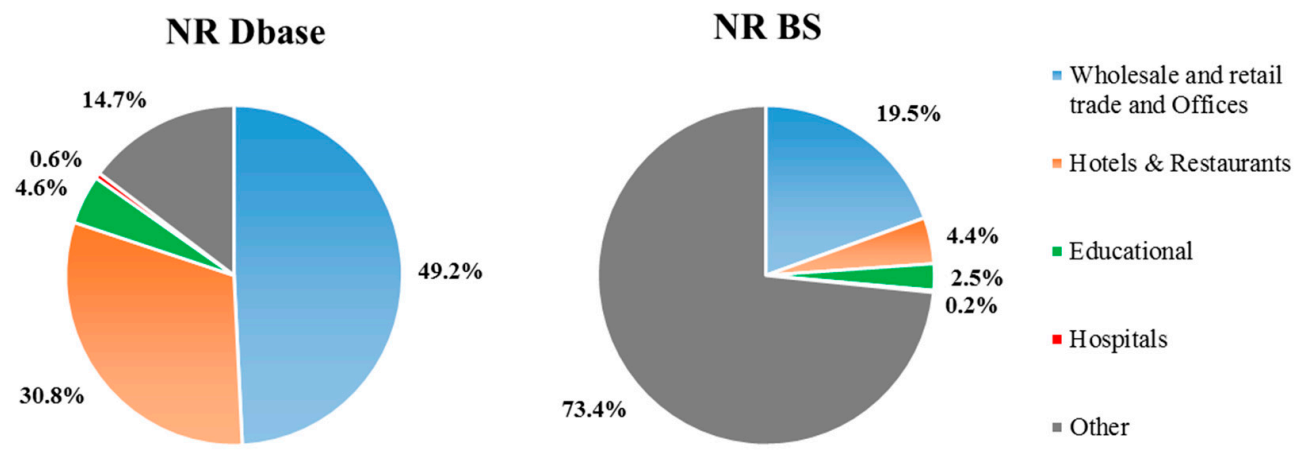

(a)
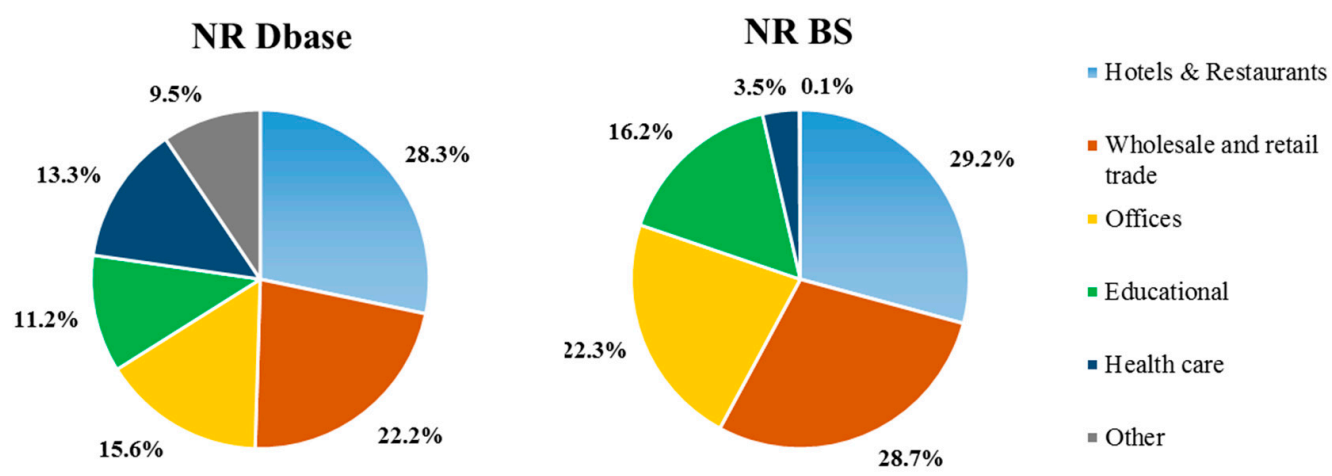

(b)

Figure 3. Distribution of (a) number of buildings and (b) total floor area of buildings in the nonresidential database from the certificates (NR Dbase) and the national building stock data (NR BS).

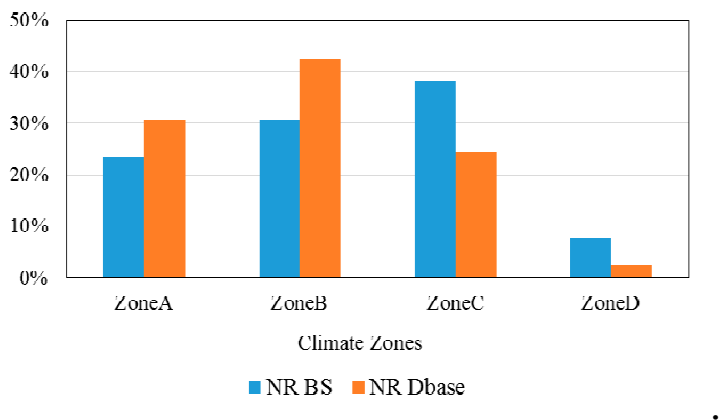

(a)

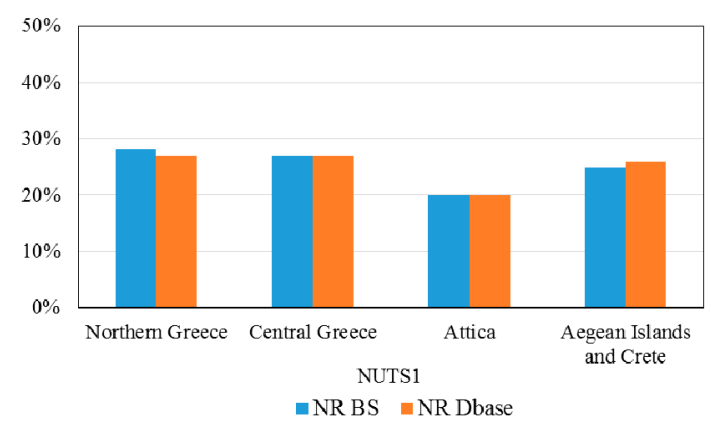

(b)

Figure 4. Spatial distribution of nonresidential buildings in the database from the certificates (NR Dbase) and the national building stock data (NR BS) (a) to climate zones and (b) to NUTS1 classification.

Analysis of the calculated primary energy per end use (Table 1) reveals that, in NR buildings, lighting is the most energy-consuming service in $40 \%$ of the BUs, followed by space heating $(33 \%)$, space cooling $(23 \%)$ and DHW $(4 \%)$. Lighting is about half of the total primary energy for some building uses like BU2-hotel (summer) and BU18 - university/college/lecture rooms, which may be attributed to the combination of high requirements for light levels and older lighting technology used. As expected, space heating is the most significant end use for school buildings, contributing up to $70 \%$ of the total in BU16 - kindergarten and 63\% in BU17-primary/secondary school, due to their unique operational characteristics (e.g., limited to the heating season and mainly morning hours). Space cooling reaches about half of the total energy use in BU10 — theater/cinema and BU11—exhibition hall/museum, mainly due to their large volumes, high internal gains and fresh air requirements. The energy use for 
DHW starts from zero for several BUs, which covers all their needs with solar collectors and reaches up to $36 \%$ for BU27-fitness center. Once again, keep in mind that for some BUs the national technical guidelines neglect the DHW demand.

The public assembly buildings (BCII) usually include building uses with many operating hours, large volumes, latent loads and internal heat gains and as a result, they exhibit the highest weighted average EUIp $\left(695.8 \mathrm{kWh} / \mathrm{m}^{2}\right)$ and $\mathrm{CO}_{2}$ emissions $\left(220.2 \mathrm{~kg} / \mathrm{m}^{2}\right)$. On the other hand, educational buildings (BCIII) have the lowest weighted average EUIp $\left(181.6 \mathrm{kWh} / \mathrm{m}^{2}\right)$ and $\mathrm{CO}_{2}$ emissions $\left(53.3 \mathrm{~kg} / \mathrm{m}^{2}\right)$, since they have limited operating hours and they don't have special energy requirements (Figure 5). As expected, DHW is not a significant end use for NR buildings. Space heating is the predominant end use for $\mathrm{BCIII}-$ educational buildings ( $58 \%$ of the total primary energy use), space cooling for BCII-public assembly buildings (37\%), while lighting for BCV-justice/public order/safety and BCI-temporary residence buildings ( $49 \%$ and $43 \%$ respectively). For the remaining $\mathrm{BCs}$, the contributions of the three end uses are more balanced.

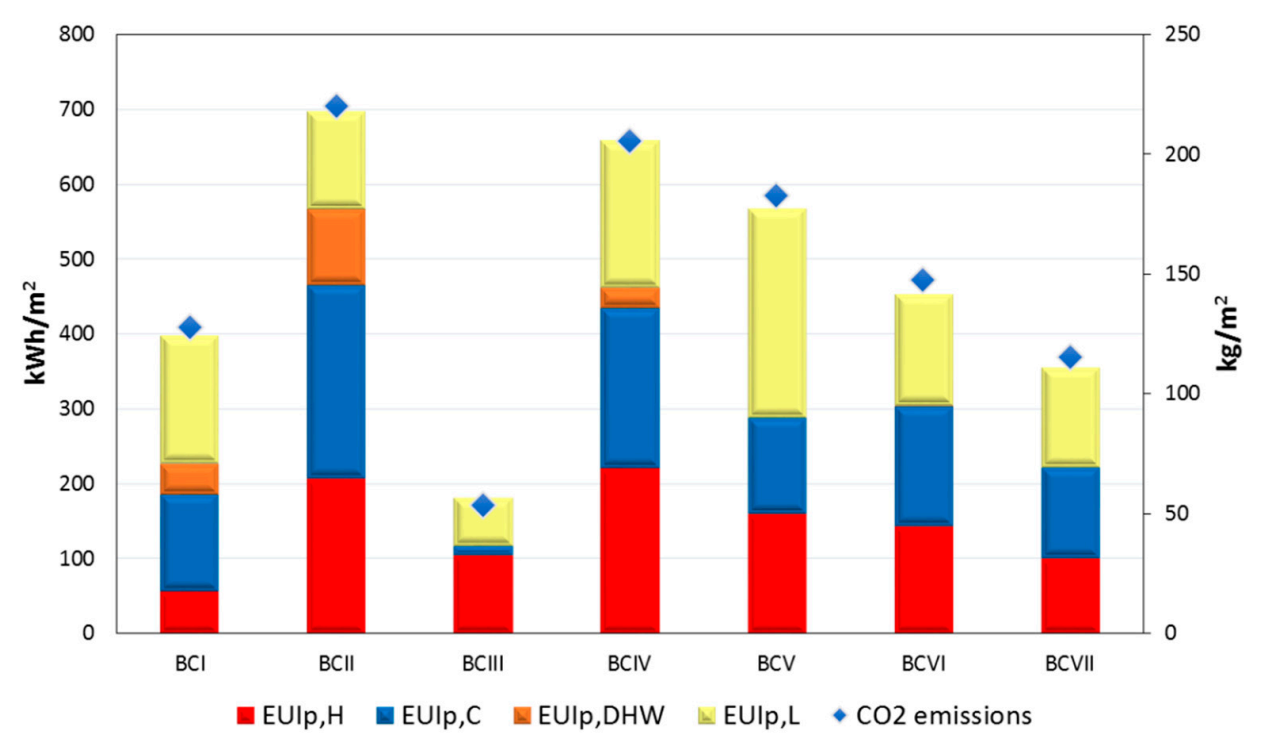

Figure 5. Weighted average primary energy use intensities (EUIp) per end use (columns, primary axis) and $\mathrm{CO}_{2}$ emissions (diamonds, secondary axis) for the seven building categories (BCI-VII).

Looking at the Hellenic NR sector, the weighted average EUIp and $\mathrm{CO}_{2}$ emissions are $448.0 \mathrm{kWh} / \mathrm{m}^{2}$ and $142.9 \mathrm{~kg} / \mathrm{m}^{2}$; this is about $26 \%$ and $52 \%$ greater than the corresponding weighted averages for the residential sector. Lighting is the most energy-consuming service (33\%), followed by cooling (32\%), heating $(29 \%)$ and DHW (6\%).

\subsection{Energy Performance}

The data analysis confirmed the relatively low energy performance of existing NR buildings in Greece (Figure 6a). About 30\% of the buildings are rated at class D; yet, this is better than the Hellenic residential buildings for which about $50 \%$ are rated at class $\mathrm{G}$ [36]. Similar results are reported in Spain [18] where NR buildings have a slightly better energy performance than residential buildings, with $26.4 \%$ of NR buildings rated at class D, followed by class E $(22.8 \%)$ and class C (19.8\%).

The weighted average energy score for each building use is presented in Figure $6 \mathrm{~b}$. Generally, all BUs have similar energy performance, with the average energy performance ranging between class $\mathrm{C}$ and class $\mathrm{E}$. The building uses with the higher energy performance (best average energy scores) are BU2-hotel (summer), BU24-police station and BU13-bank. On the other hand, the worst energy performance (lowest scores) corresponds to BU17—primary/secondary school, BU28—barber shop/hair salon and BU26-small retail building/drugstore. 


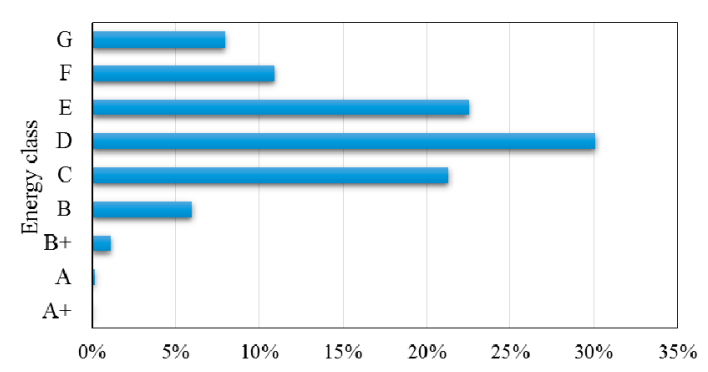

(a)

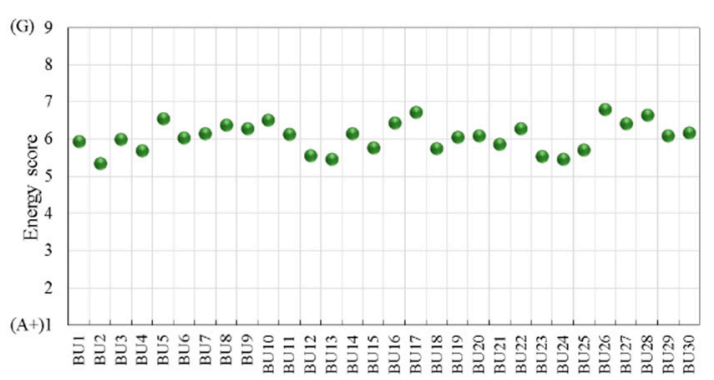

(b)

Figure 6. The distribution of NR buildings in energy classes (a) and the weighted energy score of NR buildings (b).

As expected, the average EUIp increases from the highest to the lowest energy class, ranging from $84.6 \mathrm{kWh} / \mathrm{m}^{2}$ (class A+) to $760.3 \mathrm{kWh} / \mathrm{m}^{2}$ (class G), as presented in Figure 7. Considering that $41 \%$ of the NR buildings are ranked in energy class $\mathrm{E}$ or lower, there is a significant potential for energy performance improvements by renovating the existing building stock. More insight is gained by referring to the distribution of average EUIp per energy class for the different building uses (Figure 8). The overall trend is similar, with the exception of some building uses (i.e., BU5, BU13, BU20 and BU24) for which the available sample is currently very small for detailed discretization. Overall, there is a very large range of EUIp between the highest and lowest energy class. The average decrease in EUIp between class $\mathrm{G}$ and class $\mathrm{B}$ (which corresponds to good energy behavior, according to KENAK) is about $65 \%$. Comparatively, to reach the nZEB, the EUIp of the existing buildings will have to be improved by $76 \%$, which demonstrates the challenges ahead for the national efforts to meet the ambitious energy targets in the coming decades, towards a decarbonized building stock by 2050 .

\subsection{Time Evolution of Intensities}

The periodic baselines of the primary energy use and $\mathrm{CO}_{2}$ intensities, as well as their respective standard error, according to the nine time bands, are summarized in Tables 2-7, for all building uses and building categories. Overall, there is no clear trend regarding the periodic averages amongst the different time bands. On the other hand, in most cases, standard errors are decreasing. This trend indicates that progressively the average values are becoming more accurate since there are smaller deviations in the available data.

A total of five statistical tests were applied to investigate the differentiation of the specific indicators across the eight pairs of the consecutive time bands, namely two parametric (Levene's and $t$-test) and three nonparametric (Conover, $\mathrm{M}-\mathrm{W}$ and $\mathrm{K}-\mathrm{S}$ ) tests (see Section 3.5). The $t$-test and $\mathrm{M}-\mathrm{W}$ test used to test the equality of averages, the Levene's and the Conover tests were for the equality of the variances, while the K-S test was used for the equality of the homogeneity.

As an example, the detailed results from all these tests (statistic values and p-values) as well as the retention or the rejection of the respective null hypothesis (equality of variances, averages and distributions) are summarized in Table 8 for one indicative building use (i.e., BU2-hotel (summer)). The failure codes (F-codes) summarize the rejections of the null hypothesis from the various tests, using a three-digit convention: the first digit refers to the results from the equality of averages tests; the second to the equality of the variances tests; the third to the results from the homogeneity test. For the first two digits, " 0 " represents retention of the null hypothesis in both parametric and nonparametric tests, while " 1 " signifies the rejection of the null hypothesis in at least one of the tests. For the third digit, " 0 " represents the retention of the null hypothesis in the K-S test, while " 1 " signifies its rejection. Accordingly, the nomenclature of " 000 " indicates that there is no failure in any of the tests, while " 111 " represents failure in all tests. As another example, for EUIp, L under the T2 time band "101" represents failure in the average tests (in this case both the $t$-test and the M-W test fail), no failure in any variance tests (Levene's and Conover test) and failure in the K-S test. 


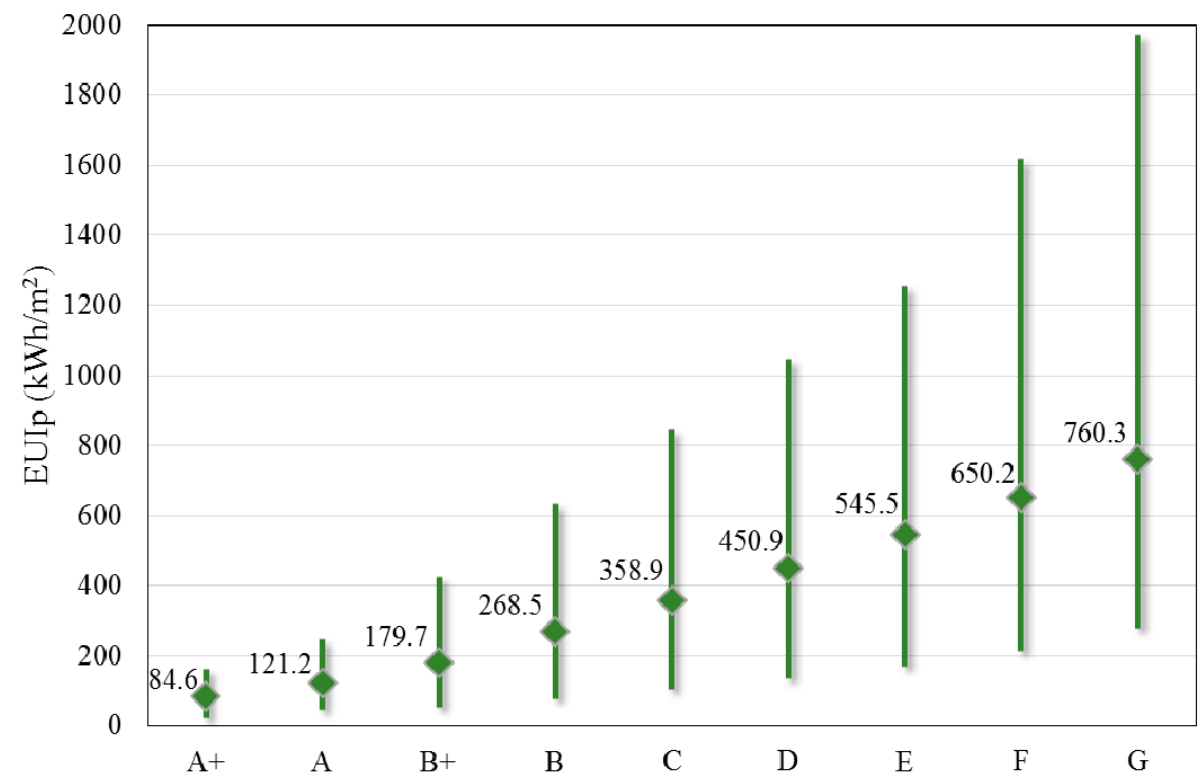

Figure 7. Calculated maximum, minimum and average (diamond) total primary energy use intensity for the different energy classes.

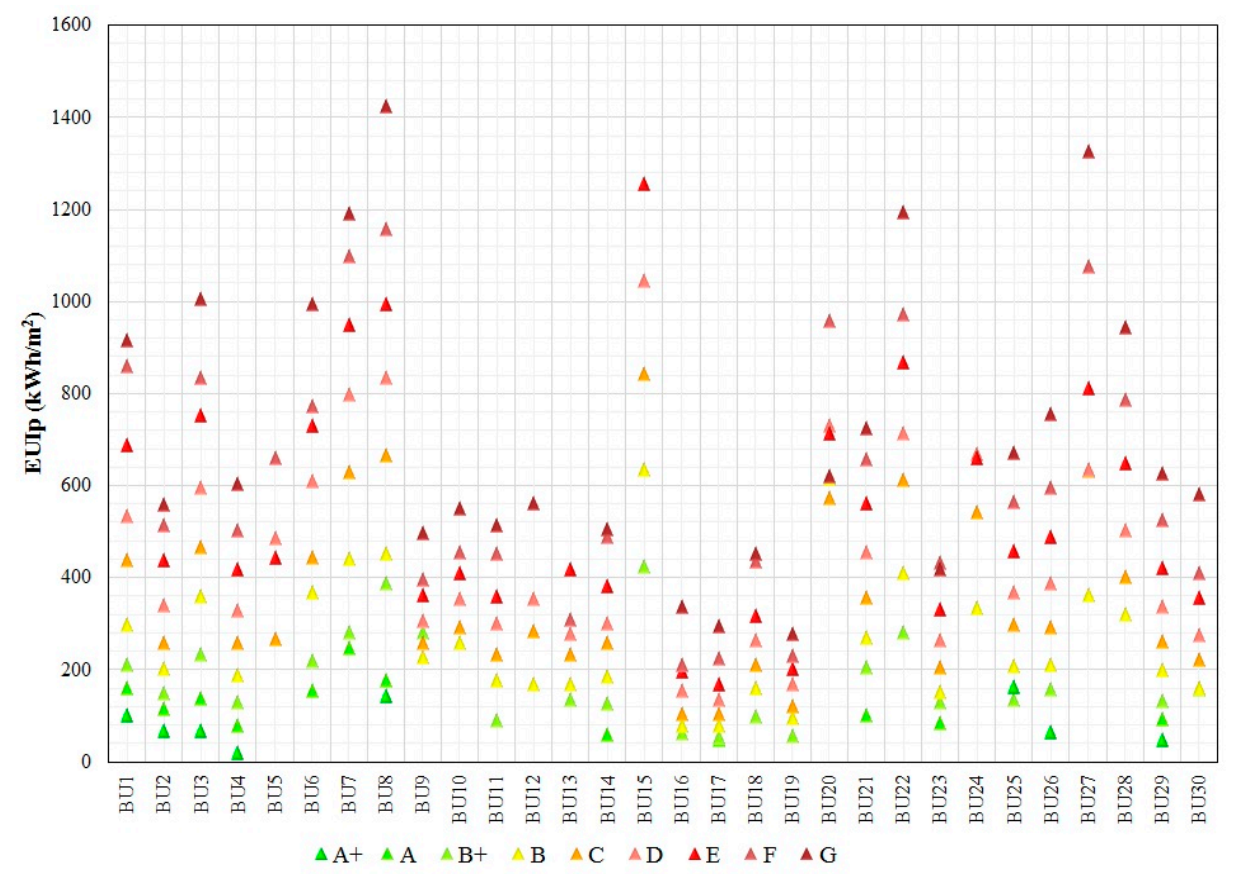

Figure 8. Calculated average primary energy use intensity per energy class (from $A+$ to $G$ ) for the various building uses ( 1 to 30 , defined in Table 1 ).

Similar results have been produced for all BUs. The failures of the various null hypothesis for the different energy use and $\mathrm{CO}_{2}$ emission intensities are summarized in Table 9, following the same three-digit nomenclature that was previously elaborated. To facilitate the interpretation of the results, failures are illustrated with shaded cells. Note that the datasets of the first two pairs of time bands (T1 and T2) that cover the early implementation years of the certification scheme, are not considered representative, due to the very small number of cases. Accordingly, these two pairs (T1 and T2) are not included in Table 9 and were not considered in the following analysis. 
Table 2. Time evolution of number of EPCs and calculated average total primary energy use for the different building categories and building uses in the NR Dbase.

\begin{tabular}{|c|c|c|c|c|c|c|c|c|c|}
\hline \multirow[b]{2}{*}{ BC } & \multicolumn{9}{|c|}{ Consecutive Time Bands } \\
\hline & Upto2011 & Upto2012 & Upto2013 & Upto2014 & Upto2015 & Upto2016 & Upto2017 & Upto2018 & Upto2019 \\
\hline BU & \multicolumn{9}{|c|}{ Number of Buildings/EUIp \pm Standard Error of the Mean $\left(\mathrm{kWh} / \mathrm{m}^{2}\right)$} \\
\hline BCI & $57 / 399.4 \pm 32.0$ & $654 / 428.0 \pm 8.0$ & $1686 / 407.6 \pm 4.8$ & $2112 / 405.3 \pm 4.2$ & $2394 / 401.1 \pm 3.9$ & $3328 / 407.6 \pm 3.4$ & $4587 / 404.8 \pm 2.9$ & $5465 / 399.0 \pm 2.6$ & $6393 / 397.3 \pm 2.4$ \\
\hline BU1 & $11 / 658.5 \pm 68.3$ & $98 / 605.1 \pm 23.4$ & $208 / 589.5 \pm 15.1$ & $268 / 581.9 \pm 12.9$ & $324 / 577.1 \pm 11.7$ & $484 / 565.7 \pm 9.2$ & $610 / 566.5 \pm 8.4$ & $758 / 551.9 \pm 7.6$ & $940 / 549.2 \pm 6.9$ \\
\hline BU2 & $40 / 265.7 \pm 19.5$ & $243 / 291.2 \pm 7.8$ & $651 / 294.3 \pm 4.1$ & $814 / 294.8 \pm 3.6$ & $943 / 291.1 \pm 3.4$ & $1181 / 292.2 \pm 3.0$ & $1686 / 295.0 \pm 2.4$ & $1947 / 294.4 \pm 2.3$ & $2270 / 295.4 \pm 2.1$ \\
\hline BU3 & $2 / 739.4 \pm 193.6$ & $118 / 608.5 \pm 18.2$ & $281 / 619.9 \pm 11.6$ & $343 / 619.6 \pm 10.7$ & $384 / 613.9 \pm 10.1$ & $559 / 603.4 \pm 8.8$ & $743 / 600.4 \pm 7.7$ & $874 / 601.6 \pm 7.1$ & $992 / 602.8 \pm 6.7$ \\
\hline BU4 & $3 / 315.8 \pm 35.2$ & $190 / 326.8 \pm 7.9$ & $535 / 327.5 \pm 4.6$ & $670 / 324.0 \pm 4.1$ & $724 / 321.0 \pm 3.9$ & $1075 / 314.7 \pm 3.2$ & $1468 / 314.0 \pm 2.8$ & $1789 / 315.1 \pm 2.6$ & $2073 / 313.4 \pm 2.4$ \\
\hline BU5 & & & $1 / 659.3$ & $4 / 437.9 \pm 100.8$ & $4 / 437.9 \pm 100.8$ & $4 / 437.9 \pm 100.8$ & $4 / 437.9 \pm 100.8$ & $9 / 433.6 \pm 46.6$ & $9 / 433.6 \pm 46.6$ \\
\hline BU6 & $1 / 640.0$ & $5 / 575.9 \pm 93.3$ & $10 / 593.5 \pm 68.1$ & $13 / 587.4 \pm 58.2$ & $15 / 557.5 \pm 57.2$ & $25 / 585.7 \pm 53.9$ & $76 / 563.3 \pm 25.0$ & $88 / 581.0 \pm 23.2$ & $109 / 597.5 \pm 21.9$ \\
\hline BCII & $50 / 863.8 \pm 67.7$ & $1053 / 741.3 \pm 12.2$ & $2073 / 710.4 \pm 8.0$ & $2473 / 703.0 \pm 7.3$ & $2743 / 692.0 \pm 6.8$ & $3726 / 672.8 \pm 5.9$ & $4581 / 662.2 \pm 5.2$ & $5249 / 695.1 \pm 5.1$ & $5955 / 695.8 \pm 4.9$ \\
\hline BU7 & $21 / 969.1 \pm 108.9$ & $452 / 901.2 \pm 16.5$ & $920 / 844.6 \pm 9.9$ & $1095 / 835.2 \pm 8.8$ & $1195 / 826.6 \pm 8.4$ & $1602 / 819.0 \pm 7.0$ & $1996 / 807.1 \pm 6.0$ & $2283 / 811.8 \pm 5.7$ & $2597 / 813.4 \pm 5.4$ \\
\hline BU8 & $17 / 995.8 \pm 144.5$ & $407 / 919.5 \pm 20.0$ & $782 / 881.7 \pm 12.4$ & $914 / 874.4 \pm 11.2$ & $993 / 869.0 \pm 10.6$ & $1384 / 863.5 \pm 8.6$ & $1687 / 863.1 \pm 7.6$ & $1897 / 881.8 \pm 7.4$ & $2153 / 899.7 \pm 7.2$ \\
\hline BU9 & $5 / 286.6 \pm 30.1$ & $104 / 336.8 \pm 11.1$ & $208 / 324.0 \pm 7.8$ & $242 / 319.1 \pm 7.0$ & $252 / 318.6 \pm 6.9$ & $324 / 318.4 \pm 5.8$ & $369 / 317.9 \pm 5.5$ & $398 / 321.1 \pm 5.3$ & $428 / 324.5 \pm 5.3$ \\
\hline${ }^{*}$ BU10 & & $8 / 387.4 \pm 23.8$ & $13 / 344.7 \pm 21.6$ & $19 / 389.1 \pm 30.2$ & $20 / 390.6 \pm 28.7$ & $30 / 366.0 \pm 21.7$ & $38 / 372.6 \pm 19.8$ & $44 / 375.8 \pm 17.9$ & $50 / 384.6 \pm 16.8$ \\
\hline * BU11 & $1 / 217.6$ & $15 / 342.1 \pm 26.8$ & $28 / 314.5 \pm 24.8$ & $34 / 322.9 \pm 23.9$ & $45 / 323.8 \pm 19.5$ & $62 / 306.7 \pm 16.4$ & $80 / 310.5 \pm 14.3$ & $103 / 315.9 \pm 12.6$ & $120 / 312.5 \pm 11.6$ \\
\hline *BU12 & & $1 / 355.1$ & $4 / 287.9 \pm 68.6$ & $4 / 287.9 \pm 68.6$ & $6 / 286.4 \pm 47.2$ & $7 / 271.6 \pm 42.5$ & $11 / 273.0 \pm 29.6$ & $14 / 313.7 \pm 37.7$ & $16 / 311.6 \pm 35.1$ \\
\hline * BU13 & / $/ 10.0 \pm 0.7$ & $6 / 293.0 \pm 33.9$ & $10 / 289.6 \pm 20.3$ & $16 / 287.6 \pm 17.1$ & $7.6 \pm 16.5$ & $8 \pm 13.6$ & $3 \pm 10.1$ & $61.8 \pm 9.6$ & $69 / 257.8 \pm 9.5$ \\
\hline * BU14 & & $26 / 298.6 \pm 21.5$ & $54 / 301.5 \pm 14.0$ & $77 / 297.9 \pm 11.4$ & $104 / 305.5 \pm 10.3$ & $150 / 308.5 \pm 8.7$ & $191 / 311.6 \pm 7.9$ & $234 / 318.4 \pm 7.8$ & $278 / 328.2 \pm 7.6$ \\
\hline BU15 & $3 / 1133.7 \pm 68.8$ & $34 / 1019.1 \pm 48.4$ & $54 / 979.8 \pm 38.3$ & $72 / 1001.2 \pm 34.1$ & $104 / 970.1 \pm 27.3$ & $130 / 977.7 \pm 23.5$ & $154 / 969.5 \pm 22.2$ & $217 / 1009.8 \pm 21.4$ & $244 / 1003.9 \pm 20.6$ \\
\hline BCIII & $15 / 224.2 \pm 27.3$ & $150 / 176.8 \pm 5.5$ & $247 / 179.3 \pm 4.6$ & $381 / 187.3 \pm 3.8$ & $657 / 174.8 \pm 2.8$ & $840 / 171.1 \pm 2.5$ & $948 / 172.1 \pm 2.3$ & $1183 / 179.7 \pm 2.2$ & $1336 / 181.6 \pm 2.1$ \\
\hline * BU16 & $1 / 206.1$ & $6 / 205.8 \pm 34.6$ & $13 / 167.5 \pm 20.2$ & $26 / 170.9 \pm 15.3$ & $59 / 166.1 \pm 9.4$ & $87 / 169.8 \pm 9.0$ & $99 / 165.9 \pm 8.5$ & $133 / 182.0 \pm 8.2$ & $152 / 177.6 \pm 7.4$ \\
\hline * BU17 & $13 / 186.0 \pm 26.5$ & $118 / 169.6 \pm 5.7$ & $154 / 169.2 \pm 5.1$ & $261 / 179.1 \pm 4.5$ & $491 / 169.1 \pm 3.3$ & $594 / 163.6 \pm 2.9$ & $650 / 164.3 \pm 2.8$ & $172.8 \pm 2.7$ & $898 / 172.0 \pm 2.6$ \\
\hline * BU18 & $1 / 290.8$ & $10 / 252.5 \pm 20.3$ & $26 / 257.2 \pm 21.6$ & $31 / 251.0 \pm 18.5$ & $36 / 245.7 \pm 16.9$ & $59 / 253.6 \pm 13.3$ & $75 / 255.3 \pm 11.4$ & $91 / 254.1 \pm 10.3$ & $116 / 254.0 \pm 8.7$ \\
\hline * BU19 & & $16 / 177.3 \pm 15.4$ & $54 / 158.9 \pm 6.4$ & $63 / 161.7 \pm 6.6$ & $71 / 162.3 \pm 6.0$ & $100 / 165.3 \pm 5.6$ & $124 / 162.9 \pm 4.9$ & $143 / 165.1 \pm 4.5$ & $170 / 167.2 \pm 4.4$ \\
\hline BCIV & $10 / 793.5 \pm 147.7$ & $60 / 555.7 \pm 44.1$ & $145 / 551.6 \pm 19.9$ & $211 / 572.7 \pm 20.4$ & $302 / 571.4 \pm 14.5$ & $412 / 607.3 \pm 13.3$ & $7.2 \pm 11.4$ & $.8 \pm 10.2$ & $796 / 657.8 \pm 9.5$ \\
\hline BU20 & $2 / 265.1 \pm 19.1$ & $3 / 471.7 \pm 206.9$ & $10 / 529.6 \pm 63.7$ & $25 / 592.0 \pm 57.9$ & $47 / 621.1 \pm 40.5$ & $65 / 650.0 \pm 34.2$ & $92 / 657.0 \pm 28.0$ & $129 / 673.4 \pm 24.0$ & $161 / 700.3 \pm 21.1$ \\
\hline BU21 & $1 / 245.6$ & $17 / 460.1 \pm 43.1$ & $38 / 470.1 \pm 29.0$ & $57 / 464.3 \pm 24.1$ & $81 / 463.2 \pm 17.9$ & $112 / 456.8 \pm 15.7$ & $164 / 437.6 \pm 11.9$ & $203 / 448.5 \pm 10.4$ & $230 / 446.7 \pm 10.1$ \\
\hline BU22 & $4 / 993.8 \pm 162$ & $10 / 865.9 \pm 90.1$ & $31 / 815.8 \pm 47.7$ & $39 / 776.5 \pm 41.6$ & $48 / 747.1 \pm 35.4$ & $69 / 698.4 \pm 33.5$ & $86 / 721.6 \pm 30.5$ & $112 / 753.1 \pm 26.1$ & $119 / 757.1 \pm 25.5$ \\
\hline BU23 & $3 / 219.1 \pm 23.7$ & $30 / 248.3 \pm 14.2$ & $66 / 258.1 \pm 10.8$ & $90 / 257.7 \pm 8.9$ & $126 / 251.8 \pm 8.2$ & $166 / 247.2 \pm 7.0$ & $203 / 241.4 \pm 6.5$ & $239 / 245.5 \pm 6.1$ & $286 / 243.5 \pm 5.6$ \\
\hline BCV & & $5 / 560.4 \pm 90.4$ & $8 / 578.4 \pm 72.8$ & $8 / 578.4 \pm 72.8$ & $9 / 575.2 \pm 64.3$ & $10 / 558.2 \pm 60.0$ & $15 / 595.5 \pm 43.3$ & $19 / 586.4 \pm 35.7$ & $22 / 566.5 \pm 35.0$ \\
\hline * BU24 & & $5 / 560.4 \pm 90.4$ & $8 / 578.4 \pm 72.8$ & $8 / 578.4 \pm 72.8$ & $9 / 575.2 \pm 64.3$ & $10 / 558.2 \pm 60.0$ & $15 / 595.5 \pm 43.3$ & $19 / 586.4 \pm 35.7$ & $22 / 566.5 \pm 35.0$ \\
\hline BCVI & $43 / 327.0 \pm 20.0$ & $1006 / 423.7 \pm 4.6$ & $2792 / 429.2 \pm 2.6$ & $3576 / 427.3 \pm 2.4$ & $4017 / 419.1 \pm 2.3$ & $6351 / 428.6 \pm 1.9$ & $8555 / 432.7 \pm 1.7$ & $9876 / 443.2 \pm 1.6$ & $11564 / 453.4 \pm 1.6$ \\
\hline * BU25 & $9 / 250.9 \pm 14.5$ & $48 / 342.7 \pm 15.1$ & $120 / 363.9 \pm 11$ & $163 / 352.6 \pm 10.4$ & $191 / 344.7 \pm 9.6$ & $262 / 345.6 \pm 8.1$ & $354 / 348.6 \pm 7.1$ & $388 / 354.2 \pm 7.0$ & $435 / 354.6 \pm 6.7$ \\
\hline * BU26 & $34 / 378.8 \pm 28.2$ & $950 / 444.1 \pm 5.1$ & $2646 / 446.2 \pm 2.9$ & $3382 / 446 \pm 2.6$ & $3795 / 443.4 \pm 2.4$ & $6035 / 452.5 \pm 2$ & $8129 / 457.9 \pm 1.8$ & $9396 / 469.3 \pm 1.8$ & $11022 / 480.5 \pm 1.8$ \\
\hline BU27 & & $5 / 568.4 \pm 110.9$ & $17 / 647.3 \pm 45.5$ & $20 / 656.4 \pm 41.9$ & $20 / 656.4 \pm 41.9$ & $29 / 666.5 \pm 35.2$ & $39 / 662.6 \pm 28.9$ & $46 / 711.0 \pm 33.0$ & $53 / 744.1 \pm 34.3$ \\
\hline BU28 & & $3 / 511.4 \pm 116.2$ & $9 / 640 \pm 63.1$ & $11 / 624.5 \pm 53.5$ & $11 / 624.5 \pm 53.5$ & $25 / 593.6 \pm 37.4$ & $33 / 578.2 \pm 32.8$ & $46 / 601.8 \pm 28.5$ & $54 / 608.8 \pm 27.0$ \\
\hline BCVII & $9 / 293.5 \pm 42.5$ & $251 / 335.3 \pm 7.7$ & $577 / 341.7 \pm 5.0$ & $769 / 338.5 \pm 4.1$ & $974 / 334.0 \pm 3.7$ & $1601 / 345.6 \pm 2.8$ & $2000 / 346.7 \pm 2.5$ & $2314 / 350.1 \pm 2.4$ & $2724 / 354.3 \pm 2.3$ \\
\hline${ }^{*}$ BU29 & $9 / 293.5 \pm 42.9$ & $249 / 335.2 \pm 7.6$ & $571 / 341.8 \pm 5.3$ & $762 / 338.5 \pm 4.4$ & $963 / 334.1 \pm 3.9$ & $1588 / 345.9 \pm 3.2$ & $1986 / 347.1 \pm 2.9$ & $2300 / 350.4 \pm 2.8$ & $2706 / 354.7 \pm 2.6$ \\
\hline * BU30 & & $2 / 360.6 \pm 87.8$ & $6 / 334 \pm 35.9$ & $7 / 333.4 \pm 30.3$ & $11 / 322.3 \pm 23.2$ & $13 / 310.5 \pm 22.8$ & $14 / 299.5 \pm 23.8$ & $14 / 299.5 \pm 23.8$ & $18 / 303.5 \pm 27.5$ \\
\hline
\end{tabular}

* BUs that have no DHW in the calculations according to the national regulation. 
Table 3. Time evolution of calculated average primary energy use for space heating for the different building categories and building uses in the NR Dbase.

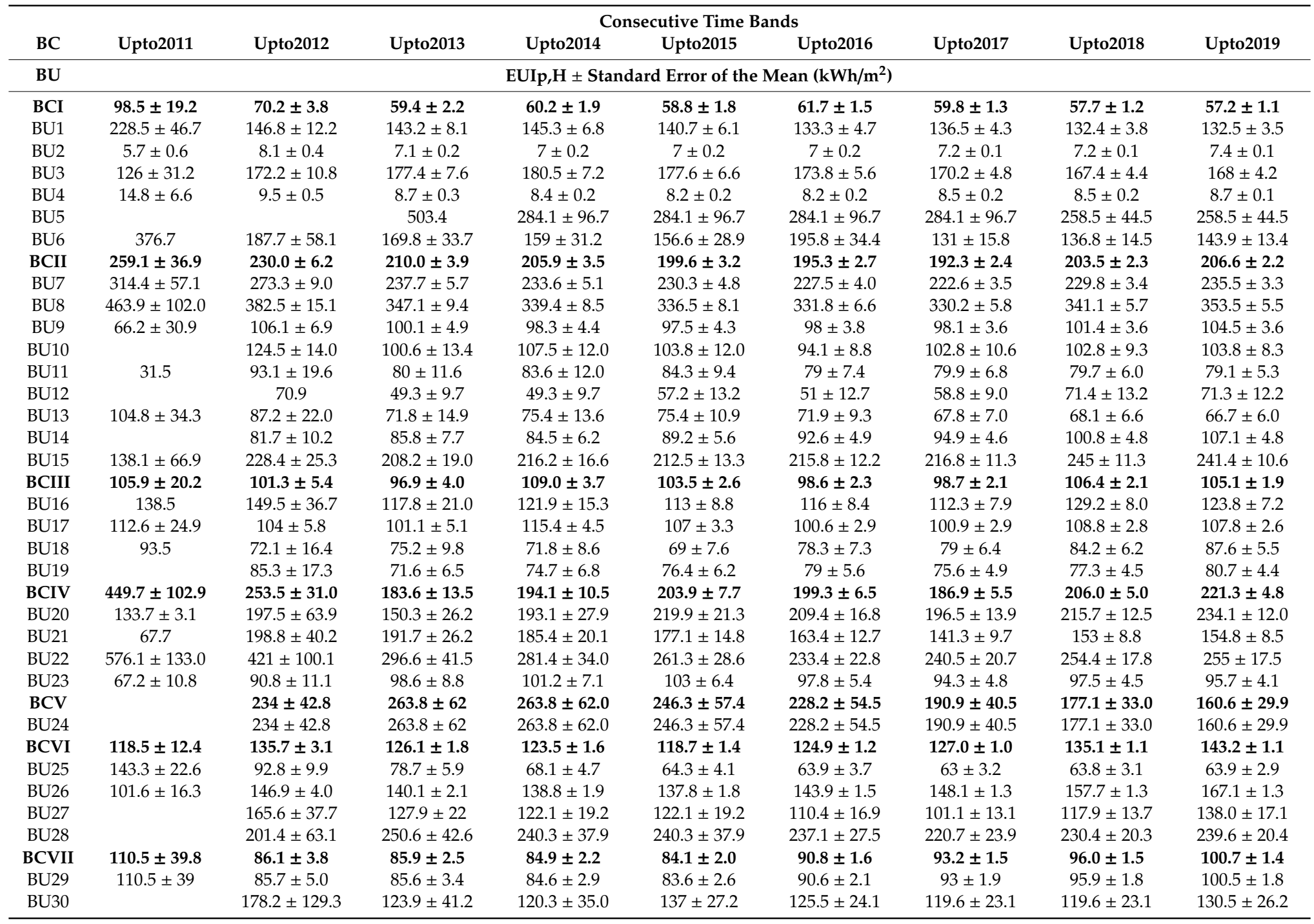


Table 4. Time evolution of calculated average primary energy use for space cooling for the different building categories and building uses in the NR Dbase.

\begin{tabular}{|c|c|c|c|c|c|c|c|c|c|}
\hline BC & \multicolumn{9}{|c|}{ Consecutive Time Bands } \\
\hline BCI & $111.0 \pm 9.5$ & $129.9 \pm 2.6$ & $124.4 \pm 1.5$ & $123.4 \pm 1.4$ & $122.7 \pm 1.3$ & $122.5 \pm 1.1$ & $123.4 \pm 0.9$ & $126.3 \pm 0.9$ & $129.5 \pm 0.8$ \\
\hline BU2 & $80.7 \pm 10.4$ & $114.7 \pm 4.7$ & $111.9 \pm 2.6$ & $111.3 \pm 2.3$ & $109.2 \pm 2.1$ & $109.2 \pm 1.9$ & $113 \pm 1.6$ & $115.9 \pm 1.5$ & $120 \pm 1.4$ \\
\hline BU3 & $91.9 \pm 1.0$ & $136 \pm 7.5$ & $137.6 \pm 4.2$ & $135.8 \pm 3.8$ & $139.4 \pm 3.8$ & $137.1 \pm 3.1$ & $137.9 \pm 2.8$ & $143.3 \pm 2.7$ & $146.7 \pm 2.5$ \\
\hline BU4 & $130.4 \pm 25.0$ & $124.4 \pm 4.4$ & $125.3 \pm 2.7$ & $122.8 \pm 2.4$ & $122 \pm 2.3$ & $117.7 \pm 1.9$ & $117.7 \pm 1.6$ & $121.9 \pm 1.5$ & $123.3 \pm 1.4$ \\
\hline BU5 & & & 2.8 & $2.1 \pm 0.2$ & $2.1 \pm 0.2$ & $2.1 \pm 0.2$ & $2.1 \pm 0.2$ & $6 \pm 2.1$ & $6 \pm 2.1$ \\
\hline BU7 & $256.8 \pm 30.0$ & $295.3 \pm 7.0$ & $276.2 \pm 4.3$ & $272.2 \pm 3.8$ & $270.2 \pm 3.6$ & $266.9 \pm 3$ & $263.8 \pm 2.6$ & $269.1 \pm 2.4$ & $272 \pm 2.3$ \\
\hline BU8 & $344 \pm 51.2$ & $321.4 \pm 8.2$ & $309.8 \pm 5.3$ & $309.1 \pm 4.8$ & $307.6 \pm 4.5$ & $306.4 \pm 3.7$ & $307.5 \pm 3.3$ & $315.7 \pm 3.2$ & $321.7 \pm 3.0$ \\
\hline BU9 & $128 \pm 16.7$ & $125 \pm 6.9$ & $120.2 \pm 4.7$ & $118.7 \pm 4.3$ & $119 \pm 4.2$ & $119.3 \pm 3.6$ & $120 \pm 3.4$ & $120.3 \pm 3.3$ & $121.1 \pm 3.2$ \\
\hline BU10 & & $213.1 \pm 12.6$ & $169.3 \pm 20.0$ & $190 \pm 17.7$ & $185.3 \pm 17.5$ & $192 \pm 13.6$ & $197.4 \pm 12.3$ & $197.9 \pm 12.1$ & $206.6 \pm 12.1$ \\
\hline BU11 & 101.5 & $192.5 \pm 16.4$ & $181.3 \pm 19.3$ & $180.6 \pm 17.6$ & $175.3 \pm 14.9$ & $161.6 \pm 12.3$ & $164 \pm 10.8$ & $166.1 \pm 9.3$ & $166 \pm 8.5$ \\
\hline BU12 & & 163.2 & $152.9 \pm 52.3$ & $152.9 \pm 52.3$ & $148.4 \pm 34.4$ & $139.2 \pm 30.5$ & $132.5 \pm 21.8$ & $134.7 \pm 17.9$ & $135.2 \pm 17.2$ \\
\hline BU13 & $81.7 \pm 13.9$ & $84.5 \pm 11.9$ & $91.2 \pm 8.8$ & $85.2 \pm 8.1$ & $93.3 \pm 9.4$ & $83.9 \pm 6.9$ & $79 \pm 5.1$ & $79.9 \pm 4.9$ & $77.7 \pm 4.6$ \\
\hline BU18 & 81.3 & $32.2 \pm 6.9$ & $35.3 \pm 4.8$ & $35.9 \pm 4.1$ & $35.6 \pm 3.7$ & $36.4 \pm 2.9$ & $37.3 \pm 2.5$ & $37.8 \pm 2.3$ & $40.4 \pm 2.1$ \\
\hline BU19 & & $9.9 \pm 1.7$ & $11.2 \pm 0.9$ & $11.1 \pm 0.8$ & $10.4 \pm 0.8$ & $10.8 \pm 0.7$ & $11 \pm 0.7$ & $10.9 \pm 0.6$ & $10.9 \pm 0.5$ \\
\hline BCIV & $152.8 \pm 34.7$ & $129.0 \pm 11.6$ & $170.3 \pm 7.8$ & $187.5 \pm 10.3$ & $177.9 \pm 7.4$ & $195.3 \pm 6.6$ & $200.5 \pm 5.7$ & $205.2 \pm 4.8$ & $212.3 \pm 4.4$ \\
\hline BU20 & $51.3 \pm 3.3$ & $137.7 \pm 86.5$ & $189.3 \pm 30.6$ & $206 \pm 29.9$ & $200.2 \pm 18.7$ & $217.6 \pm 16.4$ & $227.2 \pm 13.7$ & $225.5 \pm 10.8$ & $232.5 \pm 9.6$ \\
\hline BU21 & 13.2 & $113.1 \pm 14.6$ & $126.4 \pm 11.9$ & $124.5 \pm 9.7$ & $118.6 \pm 7.4$ & $121.8 \pm 6.4$ & $124.2 \pm 5.0$ & $122.7 \pm 4.4$ & $121.5 \pm 4.1$ \\
\hline BU22 & $191.4 \pm 49.9$ & $186.7 \pm 27.1$ & $220.2 \pm 16.8$ & $207.9 \pm 14.4$ & $204.7 \pm 11.9$ & $196.3 \pm 12.3$ & $199 \pm 10.7$ & $209.4 \pm 8.9$ & $208.4 \pm 8.5$ \\
\hline BU23 & $55 \pm 18.1$ & $66.4 \pm 7.5$ & $70.4 \pm 5.2$ & $67.6 \pm 4.9$ & $61.9 \pm 4.0$ & $62.8 \pm 3.4$ & $62.5 \pm 3.0$ & $62.9 \pm 2.7$ & $63.7 \pm 2.4$ \\
\hline BCV & & $110.6 \pm 26.9$ & $108.4 \pm 18.2$ & $108.4 \pm 18.2$ & $105.9 \pm 16.2$ & $107.9 \pm 14.7$ & $125 \pm 12.7$ & $128.7 \pm 10.4$ & $127.4 \pm 10.1$ \\
\hline BU24 & & $110.6 \pm 26.9$ & $108.4 \pm 18.2$ & $108.4 \pm 18.2$ & $105.9 \pm 16.2$ & $107.9 \pm 14.7$ & $125 \pm 12.7$ & $128.7 \pm 10.4$ & $127.4 \pm 10.1$ \\
\hline BCVI & $116.1 \pm 13.1$ & $147.1 \pm 2.5$ & $151.8 \pm 1.4$ & $152.0 \pm 1.3$ & $149.0 \pm 1.2$ & $151.5 \pm 1.0$ & $153.4 \pm 0.9$ & $157.0 \pm 0.8$ & $159.9 \pm 0.8$ \\
\hline BU25 & $88.4 \pm 8.6$ & $123.2 \pm 8.6$ & $136.5 \pm 6.2$ & $135.9 \pm 6.4$ & $131.7 \pm 5.8$ & $134 \pm 4.8$ & $139.8 \pm 4.5$ & $142.3 \pm 4.3$ & $141.7 \pm 4.1$ \\
\hline BU26 & $134.9 \pm 19.1$ & $153.3 \pm 2.8$ & $156.4 \pm 1.7$ & $156.5 \pm 1.5$ & $155.1 \pm 1.4$ & $157.1 \pm 1.1$ & $157.9 \pm 1.0$ & $161.7 \pm 0.9$ & $165.3 \pm 0.9$ \\
\hline BU27 & & $175.9 \pm 52.4$ & $147.7 \pm 23.4$ & $147.6 \pm 20.7$ & $147.6 \pm 20.7$ & $146 \pm 14.7$ & $148.9 \pm 12.2$ & $165.1 \pm 13.2$ & $173.7 \pm 13.3$ \\
\hline BU28 & & $116.4 \pm 68.3$ & $174.5 \pm 31.3$ & $167.4 \pm 25.7$ & $167.4 \pm 25.7$ & $135.5 \pm 16.7$ & $138.9 \pm 14.2$ & $153.8 \pm 12.7$ & $156.4 \pm 11.4$ \\
\hline
\end{tabular}


Table 5. Time evolution of calculated average primary energy use for DHW for the different building categories and building uses in the NR Dbase.

\begin{tabular}{|c|c|c|c|c|c|c|c|c|c|}
\hline BC & \multicolumn{9}{|c|}{ Consecutive Time Bands } \\
\hline BCI & $62.4 \pm 8.5$ & $63.9 \pm 2.1$ & $46.8 \pm 1.1$ & $45.7 \pm 1.0$ & $44.3 \pm 0.9$ & $43.8 \pm 0.7$ & $41.9 \pm 0.6$ & $41.0 \pm 0.5$ & $40.5 \pm 0.5$ \\
\hline BU2 & $50.3 \pm 3.7$ & $50.1 \pm 1.9$ & $34.9 \pm 1.1$ & $32.4 \pm 0.9$ & $30.6 \pm 0.8$ & $28.9 \pm 0.7$ & $26.7 \pm 0.6$ & $25.4 \pm 0.5$ & $24.2 \pm 0.5$ \\
\hline BU3 & $197.3 \pm 8.9$ & $85.6 \pm 6.3$ & $71.6 \pm 3.7$ & $69.2 \pm 3.2$ & $65.8 \pm 2.9$ & $61.5 \pm 2.4$ & $62.7 \pm 2.0$ & $64.2 \pm 1.9$ & $64 \pm 1.7$ \\
\hline BU4 & $60.3 \pm 26.9$ & $34.6 \pm 2.1$ & $26.3 \pm 1.1$ & $25.3 \pm 0.9$ & $25.6 \pm 0.9$ & $23.2 \pm 0.7$ & $22.7 \pm 0.6$ & $22.2 \pm 0.5$ & $22 \pm 0.5$ \\
\hline BU5 & & & 21.0 & $21.4 \pm 5.5$ & $21.4 \pm 5.5$ & $21.4 \pm 5.5$ & $21.4 \pm 5.5$ & $22.9 \pm 2.8$ & $22.9 \pm 2.8$ \\
\hline BU7 & $217 \pm 20.3$ & $185.9 \pm 3.4$ & $175.4 \pm 2.2$ & $173.5 \pm 2$ & $171 \pm 1.9$ & $168.3 \pm 1.6$ & $166.7 \pm 1.4$ & $166.3 \pm 1.3$ & $165.8 \pm 1.2$ \\
\hline BU8 & $57.8 \pm 3.4$ & $52.3 \pm 0.8$ & $50.7 \pm 0.6$ & $50.4 \pm 0.5$ & $50 \pm 0.5$ & $49.8 \pm 0.4$ & $49.6 \pm 0.4$ & $49.7 \pm 0.4$ & $49.8 \pm 0.3$ \\
\hline BU9 & $56.7 \pm 7.3$ & $55.9 \pm 1.4$ & $53.9 \pm 1.1$ & $53.6 \pm 1.0$ & $53.7 \pm 1.0$ & $53.6 \pm 0.8$ & $53.4 \pm 0.8$ & $53.4 \pm 0.8$ & $53.5 \pm 0.7$ \\
\hline \multicolumn{10}{|l|}{ * BU10 } \\
\hline \multicolumn{10}{|l|}{ *BU11 } \\
\hline \multicolumn{10}{|l|}{${ }^{*}$ BU12 } \\
\hline \multicolumn{10}{|l|}{${ }^{*}$ BU13 } \\
\hline \multicolumn{10}{|l|}{${ }^{*}$ BU18 } \\
\hline \multicolumn{10}{|l|}{ * BU19 } \\
\hline BCIV & $53.9 \pm 10.2$ & $41.2 \pm 3.6$ & $30.1 \pm 1.6$ & $29.0 \pm 1.1$ & $26.9 \pm 0.9$ & $27.5 \pm 0.9$ & $24.9 \pm 0.7$ & $26.4 \pm 0.7$ & $27.7 \pm 0.6$ \\
\hline BU20 & 7.9 & $27.5 \pm 19.6$ & $25.1 \pm 6.5$ & $29 \pm 5$ & $27.7 \pm 3.3$ & $27.6 \pm 2.7$ & $24.9 \pm 2.1$ & $27.2 \pm 1.8$ & $28.7 \pm 1.8$ \\
\hline BU21 & 41.8 & $19.1 \pm 3.3$ & $17.2 \pm 1.9$ & $15.7 \pm 1.4$ & $16.0 \pm 1.1$ & $16.3 \pm 0.9$ & $13.8 \pm 0.8$ & $13.5 \pm 0.7$ & $13.6 \pm 0.6$ \\
\hline BU22 & $63.9 \pm 19.9$ & $56.8 \pm 11.3$ & $44.1 \pm 4.9$ & $40.7 \pm 4.5$ & $38.9 \pm 3.9$ & $38.2 \pm 3.8$ & $39.6 \pm 3.5$ & $37.8 \pm 2.9$ & $37.6 \pm 2.8$ \\
\hline BU23 & $58.5 \pm 7.0$ & $34.2 \pm 3.4$ & $27.5 \pm 2.1$ & $25.9 \pm 1.7$ & $23.8 \pm 1.4$ & $22.7 \pm 1.2$ & $21.6 \pm 1$ & $21.5 \pm 1$ & $20.6 \pm 0.8$ \\
\hline \multicolumn{10}{|l|}{$B C V$} \\
\hline \multicolumn{10}{|l|}{${ }^{*}$ BU24 } \\
\hline$B C V I$ & & $1.0 \pm 0.4$ & $1.8 \pm 0.4$ & $1.6 \pm 0.3$ & $1.3 \pm 0.3$ & $1.5 \pm 0.3$ & $1.7 \pm 0.2$ & $1.7 \pm 0.2$ & $1.9 \pm 0.2$ \\
\hline \multicolumn{10}{|l|}{ * BU25 } \\
\hline \multicolumn{10}{|l|}{ * BU26 } \\
\hline BU27 & & $120.7 \pm 30.4$ & $223.4 \pm 26.0$ & $231.2 \pm 29.3$ & $231.2 \pm 29.3$ & $245.1 \pm 24.7$ & $238.7 \pm 21.7$ & $261.2 \pm 21.0$ & $268.2 \pm 19.1$ \\
\hline BU28 & & $70.3 \pm 17.0$ & $67.4 \pm 6.1$ & $67.4 \pm 5.0$ & $67.4 \pm 5.0$ & $66.4 \pm 3.8$ & $67.9 \pm 3.1$ & $68.2 \pm 2.3$ & $66.4 \pm 2.4$ \\
\hline
\end{tabular}

${ }^{*}$ BUs that have no DHW in the calculations according to the national regulation. 
Table 6. Time evolution of calculated average primary energy use for lighting for the different building categories and building uses in the NR Dbase.

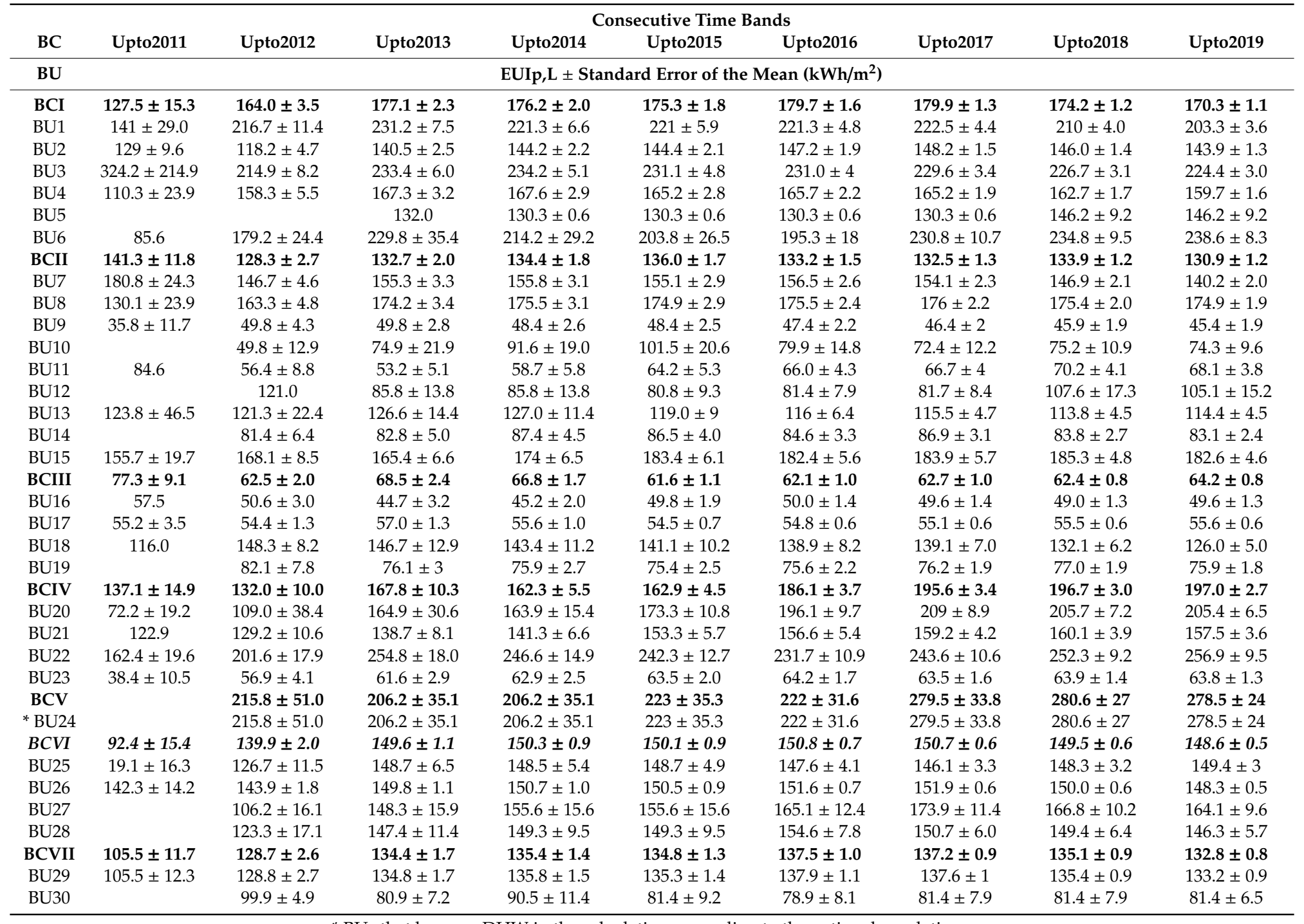

* BUs that have no DHW in the calculations according to the national regulation. 
Table 7. Time evolution of calculated average $\mathrm{CO}_{2}$ emissions intensity for the different building categories and building uses in the NR Dbase.

\begin{tabular}{|c|c|c|c|c|c|c|c|c|c|}
\hline \multirow[b]{2}{*}{ BC } & \multicolumn{9}{|c|}{ Consecutive Time Bands } \\
\hline & Upto2011 & Upto2012 & Upto2013 & Upto2014 & Upto2015 & Upto2016 & Upto2017 & Upto2018 & Upto2019 \\
\hline BU & \multicolumn{9}{|c|}{$\mathrm{CO}_{2} \pm$ Standard Error of the Mean $\left(\mathrm{kg} / \mathrm{m}^{2}\right)$} \\
\hline BCI & $131.1 \pm 1.1$ & $130.9 \pm 0.1$ & 127.9 & 127.3 & 126.5 & 129.6 & 129.5 & 127.9 & 127.9 \\
\hline BU1 & $181.9 \pm 17.9$ & $186.4 \pm 7.0$ & $183.9 \pm 4.7$ & $179.3 \pm 4.2$ & $178.8 \pm 3.7$ & $177.5 \pm 3.0$ & $178.1 \pm 2.7$ & $173.1 \pm 2.5$ & $172.9 \pm 2.2$ \\
\hline BU2 & $77.5 \pm 4.8$ & $88.5 \pm 2.4$ & $93.3 \pm 1.4$ & $94.2 \pm 1.2$ & $93.6 \pm 1.1$ & $94.4 \pm 1.0$ & $96.2 \pm 0.8$ & $96.3 \pm 0.8$ & $97.0 \pm 0.7$ \\
\hline BU3 & $236.7 \pm 50.7$ & $183.1 \pm 5.3$ & $190.9 \pm 3.6$ & $192.3 \pm 3.4$ & $191.2 \pm 3.2$ & $189.8 \pm 2.8$ & $189.0 \pm 2.4$ & $190.7 \pm 2.3$ & $191.1 \pm 2.1$ \\
\hline BU4 & $95.3 \pm 8.1$ & $101.0 \pm 2.5$ & $104.4 \pm 1.6$ & $104.1 \pm 1.4$ & $103.2 \pm 1.3$ & $102.0 \pm 1.1$ & $102.4 \pm 1.0$ & $103.5 \pm 0.9$ & $103.3 \pm 0.8$ \\
\hline BU5 & & & 177.5 & $123.7 \pm 25.5$ & $123.7 \pm 25.5$ & $123.7 \pm 25.5$ & $123.7 \pm 25.5$ & $128.5 \pm 12.0$ & $128.5 \pm 12.0$ \\
\hline BU6 & 175.9 & $175.8 \pm 27.7$ & $177.3 \pm 16.8$ & $178.9 \pm 15.0$ & $169.6 \pm 15.2$ & $182.6 \pm 17.1$ & $181.8 \pm 8.0$ & $188.2 \pm 7.4$ & $194.9 \pm 7.1$ \\
\hline BCII & $233.6 \pm 2.4$ & $218.3 \pm 0.1$ & $216.7 \pm 0.1$ & 216.2 & 213.7 & 209.3 & 206.8 & 218.9 & 220.2 \\
\hline BU7 & $269.2 \pm 29.4$ & $260.5 \pm 3.9$ & $256.8 \pm 2.6$ & $255.3 \pm 2.4$ & $253.6 \pm 2.3$ & $253.5 \pm 2.0$ & $251.5 \pm 1.7$ & $254.9 \pm 1.7$ & $257.1 \pm 1.6$ \\
\hline BU8 & $266.9 \pm 35.5$ & $260.5 \pm 5.0$ & $261.8 \pm 3.6$ & $261.8 \pm 3.3$ & $260.8 \pm 3.1$ & $261.2 \pm 2.5$ & $261.8 \pm 2.2$ & $270.3 \pm 2.3$ & $277.6 \pm 2.3$ \\
\hline BU9 & $76.0 \pm 8.6$ & $100.9 \pm 3.4$ & $101.1 \pm 2.4$ & $100.2 \pm 2.2$ & $100.2 \pm 2.1$ & $100.8 \pm 1.8$ & $101.0 \pm 1.7$ & $102.3 \pm 1.7$ & $103.5 \pm 1.7$ \\
\hline${ }^{*}$ BU10 & & $121.3 \pm 10.0$ & $108.0 \pm 7.8$ & $124.8 \pm 10.8$ & $125.7 \pm 10.3$ & $119.1 \pm 7.5$ & $122.2 \pm 6.8$ & $123.8 \pm 6.2$ & $126.8 \pm 5.8$ \\
\hline${ }^{*}$ BU11 & 69.6 & $112.0 \pm 8.6$ & $102.7 \pm 8.0$ & $105.3 \pm 7.6$ & $105.6 \pm 6.3$ & $100.3 \pm 5.4$ & $101.4 \pm 4.6$ & $103.4 \pm 4.1$ & $102.6 \pm 3.8$ \\
\hline * BU12 & & 120.7 & $97.8 \pm 23.6$ & $97.8 \pm 23.6$ & $97.4 \pm 16.2$ & $92.4 \pm 14.6$ & $91.8 \pm 10.2$ & $105.0 \pm 12.4$ & $104.0 \pm 11.5$ \\
\hline${ }^{*}$ BU13 & $86.4 \pm 19.8$ & $89.2 \pm 10.2$ & $91.6 \pm 6.4$ & $92.4 \pm 5.5$ & $93.4 \pm 5.4$ & $89.1 \pm 4.3$ & $86.5 \pm 3.2$ & $86.5 \pm 3.1$ & $85.5 \pm 3.0$ \\
\hline${ }^{*}$ BU14 & & $95.2 \pm 7.3$ & $96.5 \pm 4.5$ & $95.7 \pm 3.7$ & $98 \pm 3.3$ & $98.9 \pm 2.8$ & $100.2 \pm 2.5$ & $103.1 \pm 2.5$ & $106.9 \pm 2.5$ \\
\hline BU15 & $297.8 \pm 13.9$ & $309.5 \pm 13.6$ & $302.4 \pm 11.4$ & $312.4 \pm 10.5$ & $303 \pm 8.5$ & $307.3 \pm 7.4$ & $305.5 \pm 7.0$ & $319.6 \pm 6.8$ & $318.6 \pm 6.6$ \\
\hline BCIII & $63.5 \pm 1.9$ & $52.1 \pm 0.1$ & $53.7 \pm 0.1$ & $54.8 \pm 0.1$ & 50.3 & 49.7 & 50.1 & 52.2 & 53.3 \\
\hline * BU16 & 54.3 & $57.6 \pm 8.2$ & $48.3 \pm 5.4$ & $47.5 \pm 3.7$ & $45.7 \pm 2.2$ & $47.7 \pm 2.3$ & $47.0 \pm 2.3$ & $51.3 \pm 2.3$ & $50.5 \pm 2.0$ \\
\hline * BU17 & $49.9 \pm 6.6$ & $49.3 \pm 1.5$ & $49.6 \pm 1.4$ & $51.1 \pm 1.1$ & $47.7 \pm 0.8$ & $46.6 \pm 0.7$ & $46.8 \pm 0.7$ & $49.2 \pm 0.7$ & $49.2 \pm 0.7$ \\
\hline * BU18 & 87.4 & $81.8 \pm 5.8$ & $83.6 \pm 7.3$ & $81.3 \pm 6.2$ & $79.9 \pm 5.7$ & $82.3 \pm 4.4$ & $83.0 \pm 3.8$ & $82.7 \pm 3.4$ & $82.7 \pm 2.8$ \\
\hline * BU19 & & $57.3 \pm 4.9$ & $50.4 \pm 2.1$ & $50.9 \pm 2.0$ & $51.3 \pm 1.8$ & $52.4 \pm 1.7$ & $51.9 \pm 1.4$ & $52.8 \pm 1.4$ & $53.6 \pm 1.4$ \\
\hline BCIV & $220.3 \pm 10.1$ & $164.2 \pm 1.5$ & $172.4 \pm 0.5$ & $179.9 \pm 0.4$ & $172.9 \pm 0.3$ & $188.2 \pm 0.2$ & $190.4 \pm 0.2$ & $198.1 \pm 0.1$ & $205.6 \pm 0.1$ \\
\hline BU20 & $76.2 \pm 6.3$ & $147.7 \pm 71.6$ & $172.5 \pm 22.0$ & $187.9 \pm 19.2$ & $187.5 \pm 12.5$ & $201.6 \pm 10.9$ & $206.2 \pm 8.9$ & $210.6 \pm 7.6$ & $218.9 \pm 6.6$ \\
\hline BU21 & 61.0 & $143.2 \pm 12.9$ & $143.8 \pm 8.0$ & $142.9 \pm 6.9$ & $143.2 \pm 5.2$ & $142.6 \pm 4.6$ & $138.5 \pm 3.5$ & $140.8 \pm 3.1$ & $141.3 \pm 3.1$ \\
\hline BU22 & $275.1 \pm 42.3$ & $249.1 \pm 21.5$ & $244.7 \pm 13.5$ & $234.1 \pm 11.7$ & $226.7 \pm 10.0$ & $215.4 \pm 9.7$ & $224.0 \pm 9.1$ & $234.1 \pm 7.9$ & $235.4 \pm 7.7$ \\
\hline BU23 & $66.5 \pm 8.5$ & $76.9 \pm 4.2$ & $79.8 \pm 3.1$ & $79.8 \pm 2.7$ & $77.7 \pm 2.4$ & $76.7 \pm 2.1$ & $75.3 \pm 1.9$ & $76.3 \pm 1.8$ & $75.9 \pm 1.7$ \\
\hline BCV & & $176.0 \pm 32.7$ & $177.9 \pm 23.3$ & $177.9 \pm 23.3$ & $178.2 \pm 20.5$ & $173.8 \pm 18.9$ & $189.8 \pm 14.2$ & $188.2 \pm 11.6$ & $182.6 \pm 11.2$ \\
\hline${ }^{*}$ BU24 & & $176.0 \pm 32.7$ & $177.9 \pm 23.3$ & $177.9 \pm 23.3$ & $178.2 \pm 20.5$ & $173.8 \pm 18.9$ & $189.8 \pm 14.2$ & $188.2 \pm 11.6$ & $182.6 \pm 11.2$ \\
\hline BCVI & $90.1 \pm 1.1$ & 133.6 & 137.1 & 136.8 & 134.5 & 137.6 & 139.0 & 143.4 & 147.6 \\
\hline * BU25 & $51.7 \pm 3.2$ & $107.9 \pm 5.9$ & $119.2 \pm 4.0$ & $116.4 \pm 3.6$ & $114.3 \pm 3.3$ & $115.1 \pm 2.8$ & $116.2 \pm 2.4$ & $118.4 \pm 2.4$ & $118.6 \pm 2.3$ \\
\hline * BU26 & $116.3 \pm 8.9$ & $140.3 \pm 1.6$ & $141.8 \pm 0.9$ & $141.9 \pm 0.8$ & $141.1 \pm 0.8$ & $144.1 \pm 0.6$ & $145.8 \pm 0.5$ & $150.8 \pm 0.6$ & $155.5 \pm 0.6$ \\
\hline BU27 & & $161.8 \pm 36.6$ & $196.7 \pm 13.9$ & $201.6 \pm 13.2$ & $201.6 \pm 13.2$ & $207.8 \pm 11.6$ & $207.7 \pm 9.4$ & $225.6 \pm 11.4$ & $237.0 \pm 11.9$ \\
\hline BU28 & & $130.4 \pm 38.7$ & $187.7 \pm 21.4$ & $185.5 \pm 17.6$ & $185.5 \pm 17.6$ & $183.6 \pm 11.4$ & $182.2 \pm 10.2$ & $194.5 \pm 9.4$ & $195.7 \pm 8.9$ \\
\hline BCVII & $86.4 \pm 11.4$ & $108.6 \pm 2.4$ & $172.4 \pm 0.5$ & $109.7 \pm 1.4$ & $108.3 \pm 1.2$ & $111.8 \pm 1$ & $112.2 \pm 0.9$ & $113.6 \pm 0.9$ & $115.4 \pm 0.8$ \\
\hline * BU29 & $86.4 \pm 11.4$ & $108.6 \pm 2.4$ & $110.8 \pm 1.6$ & $109.8 \pm 1.4$ & $108.4 \pm 1.2$ & $111.9 \pm 1$ & $112.3 \pm 0.9$ & $113.7 \pm 0.9$ & $115.5 \pm 0.8$ \\
\hline * BU30 & & $106.4 \pm 17.2$ & $104.8 \pm 9.9$ & $104.7 \pm 8.4$ & $96.6 \pm 6.7$ & $94.2 \pm 6.5$ & $92.5 \pm 6.3$ & $92.5 \pm 6.3$ & $94.9 \pm 7.1$ \\
\hline
\end{tabular}

* BUs that have no DHW in the calculations according to the national regulation. 
Table 8. Results of the applied statistical tests and failure coding (F-codes) for the various energy use intensities and emissions for BU2-hotel (summer), across the eight pairs of time bands.

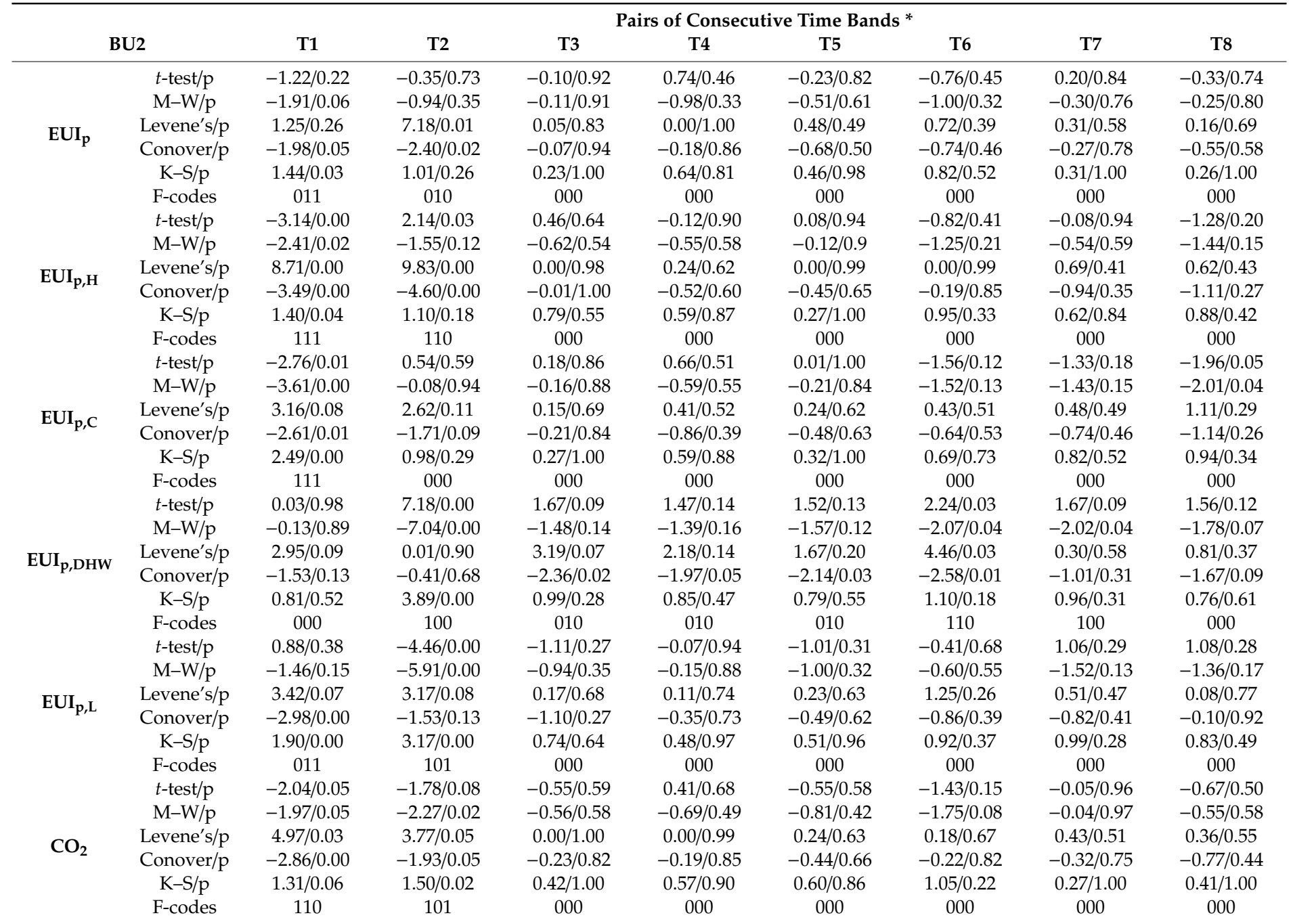

* T1:upto2011-upto2012, T2:upto2012-upto2013, T3:upto2013-upto2014, T4:upto2014-upto2015, T5:upto2015-upto2016, T6:upto2016-upto2017, T7:upto2017-upto2018, T8:upto2018-upto2019 
Table 9. Failures coding (F-codes) for primary energy uses and $\mathrm{CO}_{2}$ intensities, for the different building uses in the NR Dbase.

\begin{tabular}{|c|c|c|c|c|c|c|c|c|c|c|c|c|c|c|c|c|c|c|c|c|c|c|c|c|c|c|c|c|c|c|c|c|c|c|c|c|}
\hline & \multicolumn{36}{|c|}{ Pairs of Consecutive Time Bands } \\
\hline & 3 & $\mathrm{~T} 4$ & T5 & T6 & T7 & T8 & $\mathrm{T} 3$ & T4 & T5 & T6 & T7 & T8 & T3 & T4 & T5 & T6 & T7 & T8 & T3 $\mathrm{T}$ & $\mathrm{T} 4$ & T5 & T6 & T7 & T8 & T3 & T4 & T5 & T6 & T7 & T8 & T3 & T4 & T5 & T6 & T7 & T8 \\
\hline & \multicolumn{6}{|c|}{ EUIp } & \multicolumn{6}{|c|}{ EUIp,H } & \multicolumn{6}{|c|}{ EUIp,C } & \multicolumn{6}{|c|}{ EUIp,DHW } & \multicolumn{5}{|c|}{ EUIp,L } & \multicolumn{7}{|c|}{$\mathrm{CO}_{2}$} \\
\hline BU1 & 000 & 000 & 000 & 000 & 000 & 000 & 000 & 000 & 000 & 000 & 000 & 000 & 000 & 000 & 000 & 000 & 000 & 000 & 0000 & 000 & 000 & 000 & 000 & 000 & 000 & 000 & 000 & 000 & 101 & 000 & 000 & 000 & 000 & 000 & 000 & 000 \\
\hline BU2 & 000 & 000 & 000 & 000 & 000 & 000 & 000 & 000 & 000 & 000 & 000 & 000 & 000 & 000 & 000 & 000 & 000 & 100 & 0100 & 010 & 010 & 110 & 100 & 000 & 000 & 000 & 000 & 000 & 000 & 000 & 000 & 000 & 000 & 000 & 000 & 000 \\
\hline BU3 & 000 & 000 & 000 & 000 & 000 & 000 & 000 & 000 & 000 & 000 & 000 & 000 & 000 & 000 & 000 & 000 & 000 & 000 & 0000 & 000 & 000 & 000 & 000 & 000 & 000 & 000 & 000 & 000 & 000 & 000 & 000 & 000 & 000 & 000 & 000 & 000 \\
\hline BU4 & 000 & 000 & 000 & 000 & 000 & 000 & 000 & 000 & 000 & 000 & 000 & 000 & 000 & 000 & 000 & 000 & 000 & 000 & 0000 & 000 & 110 & 000 & 000 & 000 & 000 & 000 & 000 & 000 & 000 & 000 & 000 & 000 & 000 & 000 & 000 & 000 \\
\hline BU5 & 000 & 000 & 000 & 000 & 000 & 000 & 000 & 000 & 000 & 000 & 000 & 000 & 000 & 000 & 000 & 000 & 010 & 000 & 0000 & 000 & 000 & 000 & 000 & 000 & 000 & 000 & 000 & 000 & 010 & 000 & 000 & 000 & 000 & 000 & 000 & 000 \\
\hline BU6 & 000 & 000 & 000 & 000 & 000 & 000 & 000 & 000 & 0001 & 100 & 000 & 000 & 000 & 000 & 000 & 010 & 000 & 000 & 0000 & 000 & 000 & 110 & 000 & 000 & 000 & 000 & 000 & 000 & 000 & 000 & 000 & 000 & 000 & 000 & 000 & 000 \\
\hline BU7 & 000 & 000 & 000 & 000 & 000 & 000 & 000 & 000 & 000 & 000 & 010 & 000 & 000 & 000 & 000 & 000 & 000 & 000 & 0000 & 010 & 000 & 000 & 000 & 000 & 000 & 000 & 000 & 000 & 101 & 101 & 000 & 000 & 000 & 000 & 000 & 000 \\
\hline BU8 & 00 & 000 & 000 & 000 & 000 & 000 & 000 & 000 & 000 & 000 & 000 & 000 & 000 & 000 & 000 & 000 & 000 & 000 & 0000 & 010 & 000 & 010 & 010 & 010 & 000 & 000 & 000 & 000 & 000 & 000 & 000 & 000 & 000 & 000 & 110 & 110 \\
\hline BUS & 00 & 000 & 000 & 000 & 000 & 000 & 000 & 000 & 000 & 000 & 000 & 000 & 000 & 000 & 000 & 000 & 000 & 000 & 0000 & 000 & 000 & 000 & 000 & 000 & 000 & 000 & 000 & 000 & 000 & 000 & 000 & 000 & 000 & 000 & 0 & 000 \\
\hline BU10 & 00 & 000 & 000 & 000 & 000 & 000 & 000 & 000 & 000 & 000 & 000 & 000 & 000 & 000 & 000 & 000 & 000 & 000 & & & & & & & 000 & 000 & 010 & 000 & 000 & 000 & 000 & 000 & 000 & 000 & 000 & 000 \\
\hline BU11 & 000 & 000 & 000 & 000 & 000 & 000 & 000 & 000 & 000 & 000 & 000 & 000 & 000 & 000 & 000 & 000 & 000 & 000 & & & & & & & 000 & 000 & 000 & 000 & 010 & 000 & 000 & 000 & 000 & 000 & 000 & 000 \\
\hline BU12 & 000 & 000 & 000 & 000 & 000 & 000 & 000 & 000 & 000 & 000 & 000 & 000 & 000 & 000 & 000 & 000 & 000 & 000 & & & & & & & 000 & 000 & 000 & 000 & 000 & 000 & 000 & 000 & 000 & 000 & 000 & 000 \\
\hline BU13 & 000 & 000 & 000 & 000 & 000 & 000 & 000 & 000 & 000 & 000 & 000 & 000 & 000 & 000 & 000 & 000 & 000 & 000 & & & & & & & 000 & 000 & 000 & 000 & 000 & 000 & 000 & 000 & 000 & 000 & 000 & 000 \\
\hline BU14 & 000 & 000 & 000 & 000 & 000 & 000 & 000 & 000 & 000 & 000 & 000 & 000 & 000 & 000 & 000 & 000 & 000 & 000 & & & & & & & 000 & 000 & 000 & 000 & 000 & 000 & 000 & 000 & 000 & 000 & 000 & 000 \\
\hline BU & 00 & 000 & 000 & 000 & 000 & 000 & 000 & 000 & 000 & 000 & 000 & 000 & 000 & 000 & 000 & 000 & 000 & 000 & 0000 & 000 & 000 & 000 & 000 & 000 & 000 & 000 & 000 & 000 & 000 & 000 & 000 & 000 & 000 & 000 & 000 & 000 \\
\hline U1 & 000 & 000 & 000 & 000 & 000 & 000 & 000 & 000 & 000 & 000 & 000 & 000 & 000 & 000 & 000 & 000 & 000 & 000 & & & & & & & 000 & 000 & 000 & 000 & 000 & 000 & 000 & 000 & 000 & 000 & 000 & 000 \\
\hline BU1? & 000 & 100 & 000 & 000 & 100 & 000 & 100 & 000 & 000 & 000 & 110 & 000 & 101 & 010 & 000 & 000 & 000 & 000 & & & & & & & 000 & 000 & 000 & 000 & 000 & 000 & 000 & 100 & 000 & 000 & 100 & 000 \\
\hline BU1 & 00 & 000 & 000 & 000 & 000 & 000 & 000 & 000 & 000 & 000 & 000 & 000 & 000 & 000 & 000 & 000 & 000 & 000 & & & & & & & 000 & 000 & 000 & 000 & 000 & 000 & 000 & 000 & 000 & 000 & 000 & 000 \\
\hline BU19 & 000 & 000 & 000 & 000 & 000 & 000 & 000 & 000 & 000 & 000 & 000 & 000 & 000 & 000 & 000 & 000 & 000 & 000 & & & & & & & 000 & 000 & 000 & 000 & 000 & 000 & 000 & 000 & 000 & 000 & 000 & 000 \\
\hline BU20 & 000 & 000 & 000 & 000 & 000 & 000 & 000 & 000 & 000 & 000 & 000 & 000 & 000 & 000 & 000 & 000 & 000 & 000 & 0000 & 000 & 000 & 000 & 000 & 000 & 000 & 000 & 000 & 000 & 000 & 000 & 000 & 000 & 000 & 000 & 000 & 000 \\
\hline BU21 & 000 & 010 & 010 & 000 & 000 & 000 & 000 & 000 & 000 & 000 & 000 & 000 & 000 & 000 & 010 & 000 & 000 & 000 & 0000 & 000 & 010 & 110 & 000 & 000 & 000 & 010 & 010 & 000 & 000 & 000 & 000 & 010 & 010 & 000 & 000 & 000 \\
\hline BU22 & 000 & 000 & 000 & 000 & 000 & 000 & 000 & 000 & 000 & 000 & 000 & 000 & 000 & 000 & 000 & 000 & 000 & 000 & 0000 & 000 & 000 & 000 & 000 & 000 & 000 & 000 & 000 & 000 & 000 & 000 & 000 & 000 & 000 & 000 & 000 & 000 \\
\hline BU23 & 000 & 000 & 000 & 000 & 000 & 000 & 000 & 000 & 000 & 000 & 000 & 000 & 000 & 000 & 000 & 000 & 000 & 000 & 0000 & 000 & 000 & 000 & 000 & 000 & 000 & 000 & 000 & 000 & 000 & 000 & 000 & 000 & 000 & 000 & 000 & 000 \\
\hline BU2 & 000 & 000 & 000 & 000 & 000 & 000 & 000 & 000 & 000 & 000 & 000 & 000 & 000 & 000 & 000 & 000 & 000 & 000 & & & & & & & 000 & 000 & 000 & 000 & 000 & 000 & 000 & 000 & 000 & 000 & 000 & 000 \\
\hline BU25 & 000 & 000 & 000 & 000 & 000 & 000 & 000 & 000 & 000 & 000 & 000 & 000 & 000 & 000 & 000 & 000 & 000 & 000 & & & & & & & 000 & 000 & 000 & 000 & 000 & 000 & 000 & 000 & 000 & 000 & 000 & 000 \\
\hline BU26 & 000 & 000 & 110 & 100 & 111 & 111 & 000 & 000 & 1101 & 110 & 111 & 111 & 000 & 000 & 000 & 000 & 110 & 110 & & & & & & & 010 & 000 & 010 & 010 & 111 & 111 & 000 & 000 & 110 & 000 & 111 & 111 \\
\hline BU2 & 000 & 000 & 000 & 000 & 000 & 000 & 000 & 000 & 000 & 000 & 000 & 000 & 000 & 000 & 000 & 000 & 000 & 000 & 0000 & 000 & 000 & 000 & 000 & 000 & 000 & 000 & 000 & 000 & 000 & 000 & 000 & 000 & 000 & 000 & 000 & 000 \\
\hline BU28 & 000 & 000 & 000 & 000 & 000 & 000 & 000 & 000 & 000 & 000 & 000 & 000 & 000 & 000 & 000 & 000 & 000 & 000 & 0000 & 000 & 000 & 000 & 000 & 000 & 000 & 000 & 000 & 000 & 000 & 000 & 000 & 000 & 000 & 000 & 000 & 000 \\
\hline BU29 & 000 & 000 & 100 & 000 & 000 & 000 & 000 & 000 & 110 & 000 & 000 & 010 & 000 & 000 & 000 & 000 & 000 & 000 & & & & & & & 000 & 000 & 010 & 000 & 101 & 101 & 000 & 000 & 100 & 000 & 000 & 010 \\
\hline BU30 & 000 & 000 & 000 & 000 & 000 & 000 & 000 & 000 & 000 & 000 & 000 & 000 & 000 & 000 & 000 & 000 & 000 & 000 & & & & & & & 000 & 000 & 000 & 000 & 000 & 000 & 000 & 000 & 000 & 000 & 000 & 000 \\
\hline
\end{tabular}

the calculations according to the national regulation. 
Looking at the four end uses, the average values of energy use intensities don't differentiate significantly across the consecutive time bands in more than half of the building uses. Overall, 13 out of 30 building uses exhibit failures of the average or/and variance tests in one or more of the end uses, which might indicate that there is not yet homogeneity of the respective building uses.

Depending on the results of the statistical tests, an indicator (e.g., EUIp, EUIp,H) can be characterized as stabilized (S), almost stabilized (AS), and nonstabilized (NS), according to the discussion in Section 3.5. Based on the characterization of the respective end uses, the overall status of a building use is considered stabilized when all its end uses are stabilized, nonstabilized when at least one end use is nonstabilized, and almost stabilized in all other cases. The stabilization status of the specific indicators, as well as the overall status of all BUs are summarized in Table 10. The total primary energy use and $\mathrm{CO}_{2}$ intensity were not taken into account for the overall characterization of a $\mathrm{BU}$, since these may be the result of counteracting variations among the different end uses. Nevertheless the characterization of these two specific parameters was included in Table 10 only for comparison.

Table 10. Stabilization status for all building uses.

\begin{tabular}{|c|c|c|c|c|c|c|c|}
\hline \multirow{2}{*}{ BU } & \multicolumn{6}{|c|}{ Specific Parameters } & \multirow{2}{*}{ Overall } \\
\hline & EUIp & $\mathrm{CO}_{2}$ & EUIp,H & EUIp,C & EUIp,DHW & EUIp,L & \\
\hline BU1 & S & $\mathrm{S}$ & $\mathrm{S}$ & $\mathrm{S}$ & $S$ & NS & NS \\
\hline BU2 & $S$ & $S$ & $S$ & NS & NS & $S$ & NS \\
\hline BU3 & S & $S$ & $S$ & $\mathrm{~S}$ & $\mathrm{~S}$ & S & $\mathrm{S}$ \\
\hline BU4 & $S$ & $\mathrm{~S}$ & $S$ & $S$ & NS & S & NS \\
\hline BU5 & S & $S$ & $S$ & AS & S & AS & AS \\
\hline BU6 & $S$ & $\mathrm{~S}$ & NS & AS & NS & $S$ & NS \\
\hline BU7 & S & $S$ & AS & $S$ & AS & NS & NS \\
\hline BU8 & S & NS & $\mathrm{S}$ & $S$ & NS & NS & NS \\
\hline BU9 & S & $\mathrm{S}$ & $S$ & $S$ & $\mathrm{~S}$ & $\mathrm{~S}$ & $\mathrm{~S}$ \\
\hline BU10 & $S$ & $S$ & $S$ & $S$ & & AS & AS \\
\hline BU11 & $S$ & $S$ & $S$ & $S$ & & AS & AS \\
\hline BU12 & $S$ & $S$ & $S$ & $S$ & & $S$ & $\mathrm{~S}$ \\
\hline BU13 & $S$ & $S$ & $S$ & $S$ & & S & $S$ \\
\hline BU14 & $S$ & $S$ & $S$ & $S$ & & S & S \\
\hline BU15 & $S$ & $S$ & $S$ & $S$ & $S$ & S & S \\
\hline BU16 & $S$ & $S$ & $S$ & $S$ & & S & S \\
\hline BU17 & NS & NS & NS & NS & & S & NS \\
\hline BU18 & $S$ & $S$ & $S$ & $S$ & & S & $S$ \\
\hline BU19 & $S$ & $S$ & $S$ & $S$ & & $S$ & S \\
\hline BU20 & $S$ & $S$ & $S$ & $S$ & $S$ & S & $S$ \\
\hline BU21 & AS & AS & $S$ & AS & NS & AS & NS \\
\hline BU22 & $S$ & $S$ & $S$ & $S$ & $S$ & $\mathrm{~S}$ & $S$ \\
\hline BU23 & $S$ & $S$ & $S$ & $S$ & $S$ & S & $S$ \\
\hline BU24 & $S$ & $S$ & $S$ & $S$ & & S & S \\
\hline BU25 & $S$ & $S$ & $S$ & $S$ & & $S$ & $S$ \\
\hline BU26 & NS & NS & NS & NS & & NS & NS \\
\hline BU27 & $\mathrm{S}$ & $\mathrm{S}$ & $S$ & $S$ & $S$ & $S$ & $\mathrm{~S}$ \\
\hline BU28 & $S$ & $S$ & $S$ & $S$ & $S$ & $S$ & $S$ \\
\hline BU29 & NS & NS & NS & $S$ & & NS & NS \\
\hline BU30 & $S$ & $S$ & $S$ & $S$ & & $S$ & $S$ \\
\hline
\end{tabular}

Empty cells refer to BUs that have no DHW in the calculations according to the national regulation.

Overall, a total of 10 BUs (33\%) are nonstabilized (Table 10), indicating that the analysis results of available data should be used with caution since they might not yet be sufficiently representative of the respective building population. Among them, BU26 is the most problematic, since all of its end uses are nonstabilized, followed by BU29 and BU17, for which two out of their three end uses have not yet reached steady-state behavior. From the analysis of the available data from the NR Dbase, there were no evident reasons for nonstabilization of the specific building uses. Probably, in a second phase, 
having access and analyzing the raw data of the corresponding EPCs would allow a more detailed investigation of the driving forces for this behavior.

A similar approach was followed for the six building categories, excluding BCV since it only refers to a single building use (BU24) and was not considered again in the analysis. The temporal evolution of the weighted average primary energy use and $\mathrm{CO}_{2}$ intensities and their respective standard errors for the building categories, are also in Tables 2-7. The results are listed for the nine time bands from 2011 to 2019. For the building categories, only the two parametric statistical tests were applied, and the resulting failures of the null hypothesis are summarized in Table 11. This time, a two-digit convention is used; the first digit refers to equality of averages test and the second to equality of the variances test. The coding interpretation is the same as the one used for BUs. Again, " 0 " represents retention of the null hypothesis, while " 1 " signifies its rejection. Failures (rejections) are illustrated with shaded cells, in order to facilitate the interpretation of the results. Again, the first two pairs of time bands (T1 and T2) are not included in Table 11. Finally, the derived stabilization status is summarized in Table 12, following similar characterization rules as in the building use level. Overall, assessing the currently available data at the building category level, for the different end uses as well as for the overall behavior, the results indicate that they are nonstabilized yet. This level of detail is very demanding, so there is a need to accumulate additional data in the future.

Table 11. Failures coding (F-codes) for primary energy uses and $\mathrm{CO}_{2}$ intensities, for the different building categories in the NR Dbase.

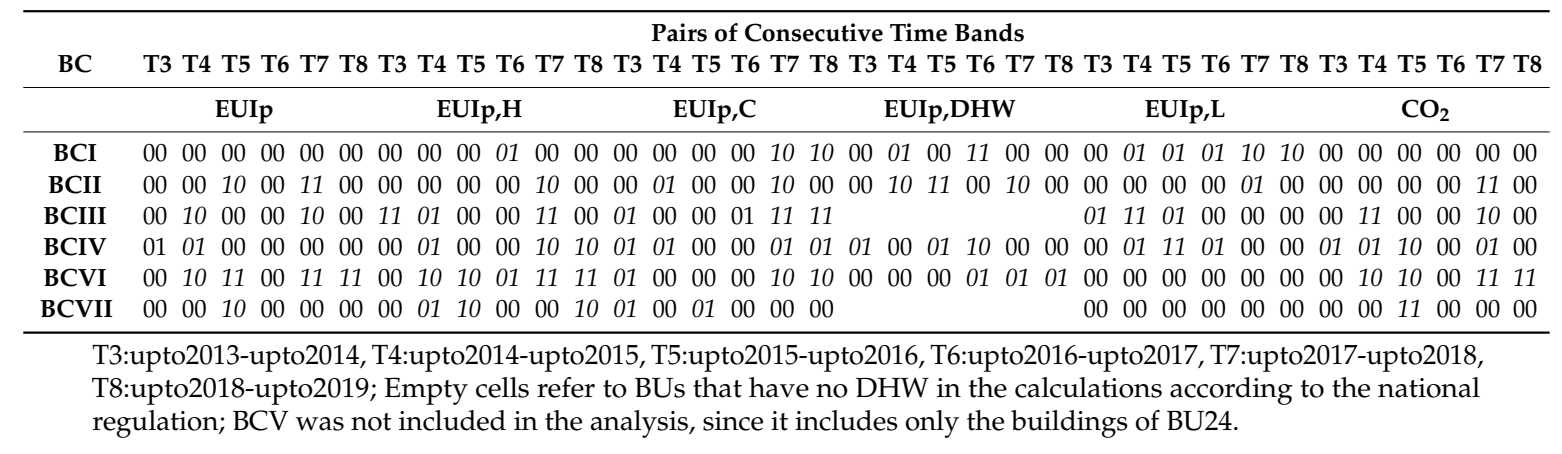

Table 12. Stabilization status for all building categories.

\begin{tabular}{cccccccc}
\hline BC & EUIp & CO $_{\mathbf{2}}$ & EUIp,H & EUIp,C & EUIp,DHW & EUIp,L & Overall \\
\hline BCI & S & S & AS & NS & NS & NS & NS \\
BCII & NS & NS & NS & NS & NS & AS & NS \\
BCIII & NS & NS & NS & NS & & NS & NS \\
BCIV & AS & NS & NS & NS & NS & NS & NS \\
BCVI & NS & NS & NS & NS & NS & S & NS \\
BCVII & NS & NS & NS & AS & & S & NS \\
\hline
\end{tabular}

Empty cells refer to BUs that have no DHW in the calculations according to the national regulation. BCV was not included in the analysis, since it includes only the buildings of BU24.

\section{Discussion and Conclusions}

This paper examined the energy performance of existing Hellenic NR buildings, by analyzing the data from about 30,000 EPCs for whole buildings that have been issued up to the end of 2019 . The data were clustered into seven building categories, according to the definitions in the national technical guidelines, and into a total of thirty building uses based on similarities between building types. The calculated primary energy use and $\mathrm{CO}_{2}$ emission intensities were analyzed, taking into account heating, cooling, DHW and lighting (heating and cooling include mechanical ventilation).

The first objective of this work was to derive practical baselines for the energy use and $\mathrm{CO}_{2}$ emission intensities for different NR buildings. Although the number of buildings in the NR Dbase is 
rather small, the total floor area of the audited buildings reaches a significant percentage of the national building stock, justifying the use of the findings as baselines, at least for most of the building uses.

The calculated primary energy use intensity for the Hellenic NR sector averages $448.0 \mathrm{kWh} / \mathrm{m}^{2}$, ranging from $167.2 \mathrm{kWh} / \mathrm{m}^{2}$ to $1003.9 \mathrm{kWh} / \mathrm{m}^{2}$ for the different buildings uses. Lighting and space cooling are the most consuming services, contributing about $33 \%$ each to the total primary energy use, following by space heating with $29 \%$ and finally by DHW with only $5 \%$. The average calculated $\mathrm{CO}_{2}$ emissions for NR buildings is $147.5 \mathrm{~kg} / \mathrm{m}^{2}$.

The relatively low energy performance of NR buildings is also reflected by their poor energy rating. They average an energy class -D by $30 \%$, while only $1.3 \%$ are ranked in energy class -B+ or better towards nZEB. Apparently, there is a great potential for significant energy conservation by renovating the existing building stock, comparing the average total primary energy use intensity to the corresponding values for the reference buildings (indicating a "good" building) as illustrated in Figure 9.

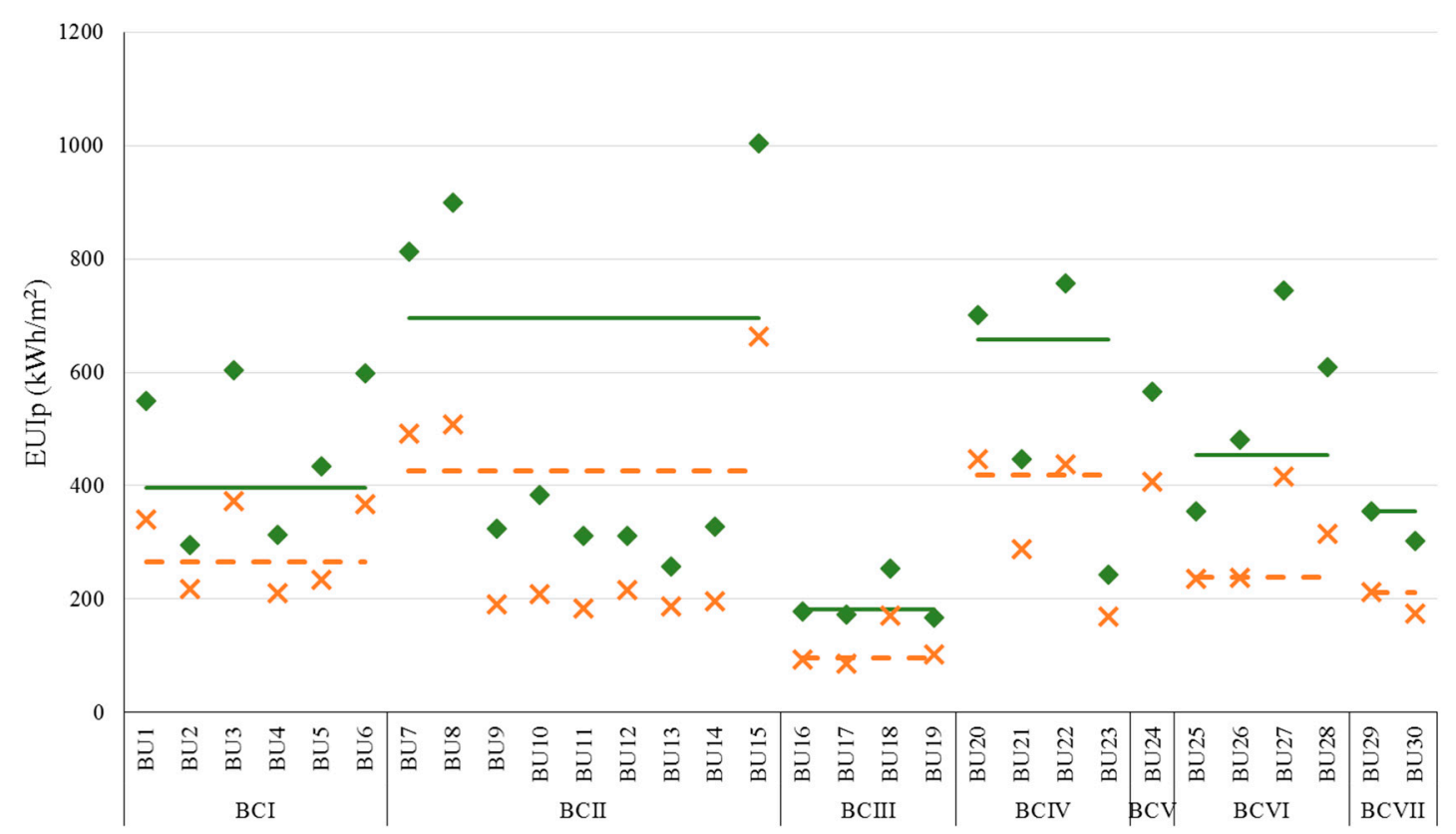

Figure 9. Calculated average total primary energy use intensity for the various building uses (diamond) and for the reference building of each BU (cross). The weighted average for the various building categories is presented with the green solid line and for the reference buildings with the orange dash line.

The primary energy use and the carbon emissions were estimated using the national conversion factors per energy carrier, which were defined in 2010. This may impact the results for electricity since they do not reflect the recent evolution of the energy mix used for power generation. This is expected to change even more in the near future, given the national efforts to decarbonize power generation and the national policy to abandon lignite power plants by 2028, according to the proposed NECP [37]. As a result, the calculated average intensities are much higher than they should be. For example, in NECP it is reported that in 2016 for electricity the conversion factor to primary energy was 2.17 and to $\mathrm{CO}_{2}$ emissions 0.606 . The use of these updated factors would result in a reduction of about $25 \%$ in the primary energy use for lighting and cooling and about $39 \%$ in $\mathrm{CO}_{2}$ emissions. The total primary energy use would also be reduced by a smaller yet significant percentage, since lighting and cooling are important end uses for NR buildings.

The second objective of this paper was to analyze the time evolution of the average primary energy use and $\mathrm{CO}_{2}$ emission intensities (arranged in nine consecutive time bands) and conclude about 
their stabilization status The cumulative datasets for first two time bands (up to 2011 and up to 2012) included very few cases and for this reason were not taken into account in the analysis.

Accordingly, for the time bands after 2013, the majority of the building uses (i.e., 19 out of 30 building uses) could be considered as stabilized, based on the test results performed on their end uses. For some of them (i.e., 11 building uses identified in Table 10) more EPCs should be gathered in order to constitute a more representative sample. Investigating only the stabilization of the EUIp (e.g., in case of lack of more detailed data), a total of 26 BUs could be considered as stabilized, indicating that when less detailed data are used, the results can be misleading. It is interesting to note that although the stabilized BUs are more than the nonstabilized ones, they represent only $28 \%$ of the total heated area, indicating that the NR Dbase as a whole is nonstabilized.

The variations in the last two pairs of consecutive time bands (T7:upto2017-upto2018 and T8:upto2018-upto2019) could be attributed to the updates incorporated in the national calculation engine in late 2017, which have affected - to some extent-the calculations of EPCs issued in 2018 and 2019. Generally, regular updating of the methodology and the software results to disruptions in the continuity of the time series, nullifying the possibility for assessing the degree of representativity of the dataset. Another limitation of the followed procedure is that for datasets with relative small number of cases, the statistical tests may not be so accurate, thus, in these cases, even if they are characterized as stabilized, more data will be required.

As expected, most of the building categories are nonstabilized, since they included heavy, nonstabilized BUs, covering between $44 \%$ and $99 \%$ of their heated area. On the other hand, BCIV is characterized nonstable, even though its only unstable building use is BU21, which corresponds to only $8 \%$ of the category's heated area. One possible cause for this is that different variations from the four building uses comprising this category may not be statistically significant at the BU level, but, when aggregated at the BC level, they became significant. This is another example of results obtained from less detailed data having the potential to be misleading, albeit at the opposite direction than the case of EUIp discussed above. In any case, even though for many BUs the population may be sufficient, when it comes to BCs, more data are required.

Furthermore, it would be desirable to evaluate and analyze the impact of the end use on EUIp in conjunction with the construction period and the climate at the location of the buildings. The national regulation recognizes three construction periods and four climate zones across Greece. However, the population of the currently available dataset is not yet sufficient to support such a discretization of the data.

As a general benefit, this work presented a well-structured integrated approach for clustering the building stock, screening the data, performing statistical tests and overall data assessment. The proposed methodology has numerous advantages, since it is a modular approach with sequential steps that can also be implemented independently, can be extended and adopted for other types of buildings (i.e., residential buildings), and can be replicated in other countries with their national certificate databases. Even if building uses and building categories are not yet all stabilized and representative, the analysis of the available data comprises a first step for bridging the gap of knowledge about the Hellenic NR building uses. The derived practical baselines on the energy use and $\mathrm{CO}_{2}$ emission intensities, elaborated for the first time at this level of detail, provide new insight for practically all NR building uses defined in Greece for gaining a deeper understanding of national building stock modeling. 
Author Contributions: Conceptualization, C.A.B. and K.G.D.; methodology, K.G.D. and C.A.B.; formal analysis, K.G.D., S.K., S.L., E.G.D. and C.A.B.; investigation, K.G.D.; data curation, K.G.D. and S.K.; writing-original draft, K.G.D.; writing-review and editing, C.A.B., S.K., S.L., E.G.D. and A.A.A.; visualization, K.G.D. All authors have read and agreed to the published version of the manuscript.

Funding: This research received no external funding.

Acknowledgments: This research is part of K.G.D. dissertation work as doctorate candidate at the Department Physics, University of Patras, Greece. The national EPC repository (buildingcert) has been developed and maintained by the Hellenic Ministry of Environment \& Energy (YPEN) in collaboration with the Centre for Renewable Energy Sources. The authors wish to acknowledge YPEN for allowing access to the EPC database. The analysis presented herein does not necessarily reflect the opinion of the Ministry.

Conflicts of Interest: The authors declare no conflict of interest.

\section{Nomenclature}

$\begin{array}{ll}\text { BC } & \text { Building Category } \\ \text { BU } & \text { Building Use } \\ \text { DHW } & \text { Domestic Hot Water } \\ \text { EED } & \text { Directive on Energy Efficiency } \\ \text { EPBD } & \text { Energy Performance of Building Directive } \\ \text { EPC } & \text { Energy performance certificate } \\ \text { EU } & \text { European } \\ \text { EUIp } & \text { Total Primary Energy Use per unit floor area } \\ \text { EUIp,H } & \text { Primary Energy Use per unit floor area for space heating } \\ \text { EUIp,C } & \text { Primary Energy Use per unit floor area for space cooling } \\ \text { EUIp,DHW } & \text { Primary Energy Use per unit floor area for domestic hot water } \\ \text { EUIp,L } & \text { Primary Energy Use per unit floor area for lighting } \\ \text { HDD } & \text { Heating Degree Days } \\ \text { IQR } & \text { Interquartile Range } \\ \text { MFH } & \text { Multifamily Houses } \\ \text { NECPs } & \text { National Energy and Climate Plan } \\ \text { NR } & \text { Nonresidential } \\ \text { NR BS } & \text { Nonresidential Building Stock } \\ \text { NR Dbase } & \text { Screened data base for NR whole-buildings from the certificates } \\ \text { SFH } & \text { Single-Family Houses }\end{array}$

\section{References}

1. European Commission. Energy Performance of Buildings. Available online: https://ec.europa.eu/energy/ en/topics/energy-efficiency/energy-performance-of-buildings/energy-performance-buildings-directive (accessed on 29 January 2020).

2. Organisation for Economic Co-Operation and Development. Built-up Area and Built-up Area Change in Countries and Regions. Available online: https://stats.oecd.org/Index.aspx?DataSetCode=BUILT_UP (accessed on 29 January 2020).

3. EU Energy in Figures. Statistical Pocketbook. 2019. Available online: https://ec.europa.eu/energy/en/dataanalysis/energy-statistical-pocketbook (accessed on 29 January 2020).

4. Bertoldi, P.; Atanasiu, B. An In-Depth Analysis of the Electricity End-Use Consumption and Energy Efficiency Trends in the Tertiary Sector of the European Union. Int. J. Green Energy 2011, 8, 306-331. [CrossRef]

5. Capros, P.; de Vita, A.; Tasios, N.; Siskos, P.; Kannavou, M.; Petropoulos, A.; Evangelopoulou, S.; Zampara, M.; Papadopoulos, D.; Nakos, C.; et al. EU Reference Scenario 2016 Energy, Transport and GHG Emissions to 2050; Publications Office of the European Union: Luxembourg, 2016. Available online: https://ec.europa.eu/energy/ sites/ener/files/documents/20160713\%20draft_publication_REF2016_v13.pdf (accessed on 29 January 2020).

6. ELSTAT. Buildings Census 2011. Athens: Hellenic Statistical Authority. 2015. Available online: www. statistics.gr/census-buildings-2011 (accessed on 29 January 2020). 
7. Gaglia, A.G.; Balaras, C.A.; Mirasgedis, S.; Georgopoulou, E.; Sarafidis, Y.; Lalas, D.P. Empirical Assessment of the Hellenic Non-Residential Building Stock, Energy Consumption, Emissions and Potential Energy Savings. Energy Convers. Manag. 2007, 48, 1160-1175. [CrossRef]

8. Hellenic Ministry of Environment \& Energy. Long Term Strategy Report Mobilizing Investments in the Renovation of Residential and Commercial Buildings, Public and Private, of the National Building Stock; Pursuant to Article 4 of Directive 2012/27/EU; Hellenic Ministry of Environment, Energy and Climatic Change: Athens, Greece, 2014.

9. European Commission. The Amending Directive. (2018/2002). Available online: https://ec.europa.eu/energy/ en/topics/energy-efficiency/targets-directive-and-rules/energy-efficiency-directive\#content-heading-0 (accessed on 29 January 2020).

10. DIRECTIVE (EU) 2018/844. Official Journal of the European Union. 2018. Available online: https://eur-lex. europa.eu/legal-content/EN/TXT/PDF/?uri=CELEX:32018L0844\&from=EN (accessed on 29 January 2020).

11. European Commission. Clean Energy for All Europeans Package. Available online: https://ec.europa.eu/energy/ en/topics/energy-strategy-and-energy-union/clean-energy-all-europeans (accessed on 29 January 2020).

12. Maldonado, E. (Ed.) Implementing the Energy Performance of Buildings Directive (EPBD); ADENE: Lisbon, Portugal, 2015.

13. Attanasio, A.; Piscitelli, M.S.; Chiusano, S.; Capozzoli, A.; Cerquitelli, T. Towards an Automated, Fast and Interpretable Estimation Model of Heating Energy Demand: A Data-Driven Approach Exploiting Building Energy Certificates. Energies 2019, 12, 1273. [CrossRef]

14. Dall'O, G.; Sarto, L.; Sanna, N.; Tonetti, V.; Ventura, M. On the use of an energy certification database to create indicators for energy planning purposes: Application in northern Italy. Energy Policy 2015, 85, $207-217$. [CrossRef]

15. Gangolells, M.; Casals, M.; Forcada, N.; Macarulla, M.; Cuerva, E. Energy mapping of existing building stock in Spain. J. Clean. Prod. 2016, 112, 3895-3904. [CrossRef]

16. Streicher, K.N.; Padey, P.; Parra, D.; Bürer, M.C.; Patel, M.K. Assessment of the current thermal performance level of the Swiss residential building stock: Statistical analysis of energy performance certificates. Energy Build. 2018, 178, 360-378. [CrossRef]

17. Dascalaki, E.G.; Kontoyiannidis, S.; Balaras, C.A.; Droutsa, K.G. Energy Certification of Hellenic Buildings: First findings. Energy Build. 2013, 65, 429-437. [CrossRef]

18. D'Agostino, D.; Cuniberti, B.; Bertoldi, P. Energy consumption and efficiency technology measures in European non-residential buildings. Energy Build. 2017, 153, 72-86. [CrossRef]

19. Gangolells, M.; Casals, M.; Ferré-Bigorra, J.; Forcada, N.; Macarulla, M.; Gaspar, K.; Tejedor, B. Energy Benchmarking of Existing Office Stock in Spain: Trends and Drivers. Sustainability 2019, 11, 6356. [CrossRef]

20. Hjortling, C.; Björk, F.; Berga, M.; af Klintberg, T. Energy mapping of existing building stock in Sweden-Analysis of data from Energy Performance Certificates. Energy Build. 2017, 153, 341-355. [CrossRef]

21. Armitage, P.; Godoy-Shimizu, D.; Steemers, K.; Chenvidyakarn, T. Using Display Energy Certificates to Quantify Public Sector Office Energy Consumption. Build. Res. Inf. 2014, 43, 691-709. [CrossRef]

22. Godoy-Shimizu, D.; Armitage, P.; Steemers, K.; Chenvidyakarn, T. Using Display Energy Certificates to Quantify Schools' Energy Consumption. Build. Res. Inf. 2011, 39, 535-552. [CrossRef]

23. Dascalaki, E.G.; Balaras, C.A.; Gaglia, A.G.; Droutsa, K.G.; Kontoyiannidis, S. Energy performance of buildings-EPBD in Greece. Energy Policy 2012, 45, 469-477. [CrossRef]

24. Ministerial Decision No 85251/242/2018-FEK 5447/B/5-12-2018 (in Greek). Available online: https: //www.e-nomothesia.gr/kat-periballon/upourgike-apophase-upendepea-85251-242-2018.html (accessed on 29 January 2020).

25. Droutsa, K.G.; Balaras, C.A.; Dascalaki, E.G.; Kontoyiannidis, S.; Argiriou, A.A. Energy Use Intensities for Asset Rating of Hellenic Non-Residential Buildings. Glob. J. Energy Technol. Res. Updates 2018, 5, 19-36. [CrossRef]

26. Arcipowska, A.; Anagnostopoulos, F.; Mariottini, F.; Kunkel, S. Energy Performance Certificates across the EU; Buildings Performance Institute Europe (BPIE): Brussels, Belgium, 2014; Available online: http://bpie.eu/wp-content/uploads/2015/10/Energy-Performance-Certificates-EPC-acrossthe-EU.-A-mapping-of-national-approaches-2014.pdf (accessed on 29 January 2020). 
27. Pasichnyi, O.; Wallin, J.; Levihn, F.; Shahrokni, H.; Kordas, O. Energy performance certificates-New opportunities for data-enabled urban energy policy instruments? Energy Policy 2019, 127, 486-499. [CrossRef]

28. Report on Quality of Statistical Data from EPCs (in Greek). Available online: http://ypeka.gr/Default.aspx? tabid=907\&language $=$ el-GR (accessed on 29 January 2020).

29. Mathew, P.A.; Dunn, L.N.; Sohn, M.D.; Mercado, A.; Custudio, C.; Walter, T. Big-data for building energy performance: Lessons from assembling a very large national database of building energy use. Appl. Energy 2015, 140, 85-93. [CrossRef]

30. Tukey, J.W. Exploratory Data Analysis. Addison-Wesley Publishing Company Reading, Mass.-Menlo Park, Cal., London, Amsterdam, Don Mills, Ontario, Sydney 1977, XVI, 688 S. Biom. J. 1981, 23, 413-414. [CrossRef]

31. Skew and Kurtosis. 2 Important Statistics Terms You Need to Know in Data Science. Available online: https://codeburst.io/2-important-statistics-terms-you-need-to-know-in-data-scienceskewness-and-kurtosis-388fef94eeaa (accessed on 29 January 2020).

32. Sprent, P. Applied Nonparametric Statistical Methods, 2nd ed.; Chapman and Hall: London, UK, 1993.

33. Homogeneity of Variance Tests. Available online: www.unistat.com/guide/homogeneity-of-variance-tests/ (accessed on 29 January 2020).

34. Levene, H. Contributions to Probability and Statistics: Essays in Honor of Harold Hotelling; Olkin, I., Ed.; Stanford University Press: Redwood City, CA, USA, 1960; pp. 278-292.

35. Devore, J. Probability and Statistics for Engineering and the Sciences, 3rd ed.; Brooks/Cole: Pacific Grove, CA, USA, 1991.

36. Droutsa, K.G.; Kontoyiannidis, S.; Dascalaki, E.G.; Balaras, C.A. Mapping the Energy Performance of Hellenic Residential Buildings from EPC (energy performance certificate) Data. Energy 2016, 98, 284-295. [CrossRef]

37. National Plan for Energy and Climate (in Greek). Available online: www.opengov.gr/minenv/?p=10155 (accessed on 29 January 2020).

(C) 2020 by the authors. Licensee MDPI, Basel, Switzerland. This article is an open access article distributed under the terms and conditions of the Creative Commons Attribution (CC BY) license (http://creativecommons.org/licenses/by/4.0/). 